\title{
Using photorespiratory oxygen response to analyse leaf mesophyll resistance
}

\author{
Xinyou Yin $^{1}$ (1) Peter E. L. van der Putten ${ }^{1} \cdot$ Daniel Belay $^{2} \cdot$ Paul C. Struik $^{1}$
}

Received: 27 November 2019 / Accepted: 27 January 2020 / Published online: 10 February 2020

(c) The Author(s) 2020

\begin{abstract}
Classical approaches to estimate mesophyll conductance ignore differences in resistance components for $\mathrm{CO}_{2}$ from intercellular air spaces (IAS) and $\mathrm{CO}_{2}$ from photorespiration $(F)$ and respiration $\left(R_{\mathrm{d}}\right)$. Consequently, mesophyll conductance apparently becomes sensitive to (photo)respiration relative to net photosynthesis, $\left(F+R_{\mathrm{d}}\right) / A$. This sensitivity depends on several hard-to-measure anatomical properties of mesophyll cells. We developed a method to estimate the parameter $m(0 \leq m \leq 1)$ that lumps these anatomical properties, using gas exchange and chlorophyll fluorescence measurements where $\left(F+R_{\mathrm{d}}\right) / A$ ratios vary. This method was applied to tomato and rice leaves measured at five $\mathrm{O}_{2}$ levels. The estimated $m$ was 0.3 for tomato but 0.0 for rice, suggesting that classical approaches implying $m=0$ work well for rice. The mesophyll conductance taking the $m$ factor into account still responded to irradiance, $\mathrm{CO}_{2}$, and $\mathrm{O}_{2}$ levels, similar to response patterns of stomatal conductance to these variables. Largely due to different $m$ values, the fraction of (photo)respired $\mathrm{CO}_{2}$ being refixed within mesophyll cells was lower in tomato than in rice. But that was compensated for by the higher fraction via IAS, making the total re-fixation similar for both species. These results, agreeing with $\mathrm{CO}_{2}$ compensation point estimates, support our method of effectively analysing mesophyll resistance.
\end{abstract}

Keywords $\mathrm{CO}_{2}$ compensation point $\cdot \mathrm{CO}_{2}$ transfer $\cdot$ Internal conductance $\cdot \mathrm{O}_{2}$ response $\cdot$ Resistance $\cdot$ Re-assimilation

\section{Introduction}

Quantifying the $\mathrm{CO}_{2}$ diffusion inside leaves of $\mathrm{C}_{3}$ plants is important in both physiological and ecological contexts. Physiologists assess leaf photosynthetic efficiency and capacity, and both of them depend on how $\mathrm{CO}_{2}$ from the atmosphere travel to the chloroplast stroma and how much $\mathrm{CO}_{2}$ released by respiration and photorespiration ["(photo) respired $\mathrm{CO}_{2}$ " hereafter] can be refixed by Rubisco (Busch et al. 2013; von Caemmerer 2013). Ecologists often project the impact of global land $\mathrm{CO}_{2}$ fertilization (Sun et al.

Electronic supplementary material The online version of this article (https://doi.org/10.1007/s11120-020-00716-z) contains supplementary material, which is available to authorized users.

Xinyou Yin

Xinyou.yin@wur.nl

1 Centre for Crop Systems Analysis, Wageningen University \& Research, P.O. Box 430, 6700 AK Wageningen, The Netherlands

2 Selale University, P.O. Box 245, Fiche, Ethiopia
2014). The model of Farquhar, von Caemmerer and Berry (1980; "the FvCB model" hereafter), which is widely used as a component for this projection, requires the $\mathrm{CO}_{2}$ level at carboxylation sites of Rubisco $\left(C_{\mathrm{c}}\right)$ as its input. The drawdown of $C_{\mathrm{c}}$, relative to the $\mathrm{CO}_{2}$ level in the ambient air $\left(C_{\mathrm{a}}\right)$, depends not only on stomatal conductance for $\mathrm{CO}_{2}$ transfer $\left(g_{\mathrm{sc}}\right)$ but also on mesophyll conductance $\left(g_{\mathrm{m}}\right)$, such that (von Caemmerer and Evans 1991):

$C_{\mathrm{c}}=C_{\mathrm{i}}-A / g_{\mathrm{m}}$

where $C_{\mathrm{i}}$ is the intercellular air space (IAS) $\mathrm{CO}_{2}$ level and $A$ is the net photosynthesis rate.

The FvCB model calculates $A$ as the minimum of the Rubisco activity limited rate $\left(A_{\mathrm{c}}\right)$ and electron transport-limited rate $\left(A_{\mathrm{j}}\right)$ of photosynthesis, and Sharkey (1985) added a third limitation, accounting for the rate set by triose phosphate utilization $\left(A_{\mathrm{p}}\right)$ (see Supplementary Text S1). Equation (1) has been combined with the FvCB model to estimate $g_{\mathrm{m}}$ from combined data of gas exchange and chlorophyll fluorescence measurements on photosystem II (PSII) electron transport efficiency $\Phi_{2}$ (Harley et al. 1992; Yin and Struik 2009). The most commonly used method to estimate $g_{\mathrm{m}}$ is 
the 'variable J method' (Harley et al. 1992), derived from the $A_{\mathrm{j}}$ part of the FvCB model, using measurements that have to include photorespiratory conditions (Laisk et al. 2006; see Supplementary Text S2). Equation (1) has also been used to estimate $g_{\mathrm{m}}$ from online carbon isotope discrimination measurements (e.g. Evans et al. 1994; Tazoe et al. 2011; Barbour et al. 2016a) or oxygen isotope techniques (Barbour et al. 2016b).

Equation (1), as the classical $g_{\mathrm{m}}$ model, treats the (photo) respired $\mathrm{CO}_{2}$ in the same way as it treats the $\mathrm{CO}_{2}$ flux that comes from the IAS. Mesophyll resistance (the inverse of mesophyll conductance) consists of components imposed by IAS, cell wall, plasmalemma, cytosol, chloroplast envelope and stroma (Evans et al. 2009; Terashima et al. 2011). Unlike the $\mathrm{CO}_{2}$ from the IAS, the (photo)respired $\mathrm{CO}_{2}$, mainly coming from the mitochondria, does not need to cross the cell wall and plasmalemma, and thus experiences a different resistance. For this reason, Tholen et al. (2012) developed an Equation for the drawdown of $C_{\mathrm{c}}$, relative to $C_{\mathrm{i}}$ :

$C_{\mathrm{c}}=C_{\mathrm{i}}-A\left(r_{\mathrm{wp}}+r_{\mathrm{ch}}\right)-\left(F+R_{\mathrm{d}}\right) r_{\mathrm{ch}}$

where $F$ and $R_{\mathrm{d}}$ are $\mathrm{CO}_{2}$ fluxes from photorespiration and respiration, respectively, $r_{\mathrm{wp}}$ is the combined cell wall and plasma membrane resistance, and $r_{\mathrm{ch}}$ is the chloroplast envelope and stroma resistance $\left(r_{\mathrm{ch}}\right)$. Combining Eqs. (1) and (2) results in $g_{\mathrm{m}}=1 /\left[r_{\mathrm{wp}}+r_{\mathrm{ch}}+r_{\mathrm{ch}}\left(F+R_{\mathrm{d}}\right) / A\right]$. Tholen et al. (2012) concluded that mesophyll conductance, as defined by Eq. (1), is influenced by the ratio of (photo)respired $\mathrm{CO}_{2}$ release to net $\mathrm{CO}_{2}$ uptake, $\left(F+R_{\mathrm{d}}\right) / A$, thereby resulting in an apparent sensitivity of mesophyll conductance to $\left[\mathrm{CO}_{2}\right]$ and $\left[\mathrm{O}_{2}\right]$. As this sensitivity does not imply a change in intrinsic diffusion properties, $g_{\mathrm{m}}$ as defined by Eq. (1) is an apparent parameter. We shall call it the apparent mesophyll conductance $\left(g_{\mathrm{m} \text {,app }}\right)$. In developing their model, Tholen et al. (2012) assumed a negligible IAS and cytosol resistance, but Eq. (2) still holds if the IAS resistance is lumped into $r_{\mathrm{wp}}$, and part of cytosol resistance is lumped into $r_{\mathrm{wp}}$, and the remaining part is lumped into $r_{\mathrm{ch}}$ (Berghuijs et al. 2015). If $r_{\mathrm{wp}}$ and $r_{\mathrm{ch}}$ both represent physical resistances, the total mesophyll diffusion resistance $\left(r_{\mathrm{m} \text {,dif }}\right)$ is $r_{\mathrm{wp}}+r_{\mathrm{ch}}$, and the model of Tholen et al. can be rewritten as

$g_{\mathrm{m}, \mathrm{app}}=\frac{1}{r_{\mathrm{m}, \mathrm{dif}}\left[1+\omega\left(F+R_{\mathrm{d}}\right) / A\right]}$

where $\omega$ is the fraction of $r_{\mathrm{ch}}$ in $r_{\mathrm{m} \text {,dif }}$.

However, the relative position of mitochondria and chloroplasts is underrepresented in the model of Tholen et al. (2012). Considering six scenarios of the arrangement of these organelles, Yin and Struik (2017) derived the model: $g_{\text {m,app }}=1 /\left\{r_{\text {m,dif }}\left[1+\omega(1-\lambda k)\left(F+R_{\mathrm{d}}\right) / A\right]\right\}$, where $\lambda$ is the fraction of mitochondria located in the inner cytosol (i.e. the cytosol area between chloroplasts and vacuole), and $k$ is a factor allowing an increase $(k>1)$, no change $(k=1)$, and a decrease $(0 \leq k<1)$ in the fraction of inner (photo)respired $\mathrm{CO}_{2}$, caused by gaps when chloroplasts are not continuously aligned. The gaps largely depend on the anatomical parameter $S_{\mathrm{c}} / S_{\mathrm{m}}$, the ratio of chloroplast area to the mesophyll area exposed to IAS (Sage and Sage 2009). As $(1-\lambda k)$ is between 0 and 1 , the model predicts that the sensitivity of $g_{\text {m,app }}$ to $\left(F+R_{\mathrm{d}}\right) / A$ is lower than Tholen et al. (2012) initially stated (Yin and Struik 2017). The model of Tholen et al. applies to an extreme case, either where mitochondria are located exclusively in the outer cytosol between plasmalemma and chloroplasts $(\lambda=0)$ or where (photo)respired $\mathrm{CO}_{2}$ are completely mixed in cytosol if cytosol resistance is negligible and there are chloroplast gaps $(k \rightarrow 0)$. In another extreme case where mitochondria are located exclusively in the inner cytosol $(\lambda=1)$ and chloroplasts cover completely the cell periphery $(k=1)$, the model predicts no sensitivity of $g_{\mathrm{m} \text {,app }}$ to $\left(F+R_{\mathrm{d}}\right) / A$, and Eq. (1) would work well as $g_{\mathrm{m} \text {,app }}$ becomes $g_{\mathrm{m} \text {,dif }}\left(=1 / r_{\mathrm{m} \text {,dif }}\right)$. Equation (1) also works when $r_{\mathrm{ch}}$ is negligible compared to $r_{\mathrm{wp}}(\omega=0)$ as if (photo) respired $\mathrm{CO}_{2}$ is released in the same organelle where RuBP carboxylation occurs. Either situation $(\lambda k=1$ or $\omega=0)$ can be approximately represented by leaves where mitochondria lies only in the inner cytosol, intimately behind chloroplasts that form a continuum.

Most likely scenarios are somewhere between the two extremes defined by Eqs. (1) and (2), that is, $0<\lambda k<1$ and $0<\omega<1$. All these scenarios result in different fractions of re-assimilation of (photo)respired $\mathrm{CO}_{2}$ (Yin and Struik 2017), both within mesophyll cells and via IAS (see Supplementary Text S3). It would be useful if $\omega, \lambda$ and $k$ can be measured. One way to derive $\omega$ is to use individual resistances that can be calculated from microscopic measurements on leaf anatomy (Evans et al. 1994; Peguero-Pino et al. 2012; Tosen et al. 2012a, b; Tomas et al. 2013; Berghuijs et al. 2015), despite uncertainties in the value of gas diffusion coefficients. Another possible method to estimate $\omega$ is to first estimate $r_{\text {wp }}$ from oxygen isotope techniques assuming that the outer limit of carbonic anhydrase activity represents the cytosol immediately adjacent to the cell wall (Barbour 2017). Parameter $\lambda$ can be assessed using electron microscope images for mitochondria distribution (Hatakeyama and Ueno 2016). Most difficult is to measure $k$, which depends on $S_{\mathrm{c}} / S_{\mathrm{m}}$. However, whether a high $S_{\mathrm{c}} / S_{\mathrm{m}}$ would make $k>1$ or $<1$ would depend on the $\lambda$ value as well as on cytosol resistance, and such a complex relationship is hard to quantify with a simple resistance model. However, because $\omega, \lambda$ and $k$ lump together co-defining the sensitivity of $g_{\text {m,app }}$ to $\left(F+R_{\mathrm{d}}\right) / A$, the model of Yin and Struik (2017) can be rewritten to 
$g_{\mathrm{m}, \mathrm{app}}=\frac{1}{r_{\mathrm{m}, \mathrm{dif}}\left[1+m\left(F+R_{\mathrm{d}}\right) / A\right]}$

where $m=\omega(1-\lambda k)$. Although Eq. (3) looks the same as Eq. (2a), their underlying intracellular fluxes for $\mathrm{CO}_{2}$ gradient and re-assimilation differ (see Supplementary Text S3). Equation (3) may be used for estimating $m$ from noninvasive gas exchange measurements where $\left(F+R_{\mathrm{d}}\right) / A$ varies.

Many reports (e.g. Flexas et al. 2007a; Vrábl et al. 2009; Yin et al. 2009; Tazoe et al. 2011) showed that $g_{\mathrm{m} \text {,app }}$ responds to changes in $\left[\mathrm{CO}_{2}\right]$ or irradiance levels. $g_{\mathrm{m} \text {,app }}$ was shown in tobacco to increase when $\left[\mathrm{O}_{2}\right]$ was decreased from 21 to $1 \%$ (Tholen et al. 2012). All these responses can be described using a phenomenological equation (Yin et al. 2009). Tholen et al. (2012) explained the $\mathrm{O}_{2}$ response and the commonly observed decline of $g_{\text {m,app }}$ with decreasing $\mathrm{CO}_{2}$ below the ambient level (e.g. Flexas et al. 2007a; Vrábl et al. 2009; Yin et al. 2009), based on the earlier introduced sensitivity of $g_{\mathrm{m} \text {,app }}$ to $\left(F+R_{\mathrm{d}}\right) / A$, because both increasing $\mathrm{O}_{2}$ and decreasing $C_{\mathrm{i}}$ increase $\left(F+R_{\mathrm{d}}\right) / A$. However, the sensitivity of $g_{\mathrm{m} \text {,app }}$ to $\left(F+R_{\mathrm{d}}\right) / A$ cannot explain the observed response of $g_{\mathrm{m} \text {,app }}$ to irradiances. Moreover, it is unknown whether $g_{\mathrm{m} \text {,dif }}$ would be conserved across irradiance, $\mathrm{CO}_{2}$ and $\mathrm{O}_{2}$ levels.
In this study, we described a method that explores varying $\left(F+R_{\mathrm{d}}\right) / A$ ratios to analyse mesophyll resistance from combined gas exchange and chlorophyll fluorescence measurements. The varying $\left(F+R_{\mathrm{d}}\right) / A$ ratios were mainly created using five levels of $\mathrm{O}_{2}$, on two contrasting species tomato and rice. Using these data, we assessed (i) the value of the $m$ factor and whether it differs between species, (ii) whether $g_{\mathrm{m} \text {,dif }}$ responds to $\left[\mathrm{CO}_{2}\right]$, irradiance and $\left[\mathrm{O}_{2}\right]$, and (iii) how the re-assimilation of (photo)respired $\mathrm{CO}_{2}$ is affected by the $m$ factor.

\section{Materials and methods}

\section{Experiments and growth conditions}

Seeds of tomato and rice were sown, and uniform seedlings were transplanted into pots 2 weeks after sowing, in glasshouse compartments. Pots were filled with soil, and after assessing initial soil nutrient contents, extra nutrients were applied (Table 1). Tomato plants were watered regularly, while rice plants were maintained submerged.

About $60 \%$ of the radiation incident on the glasshouse was transmitted to the plant level. During daytime supplemental light from $600 \mathrm{~W}$ HPS Hortilux Schréder lamps

Table 1 Growth and measurement conditions during the experiments with tomato and rice

\begin{tabular}{|c|c|c|}
\hline & Tomato (cv. Growdena) & Rice (cv. IR64) \\
\hline \multicolumn{3}{|l|}{ Growth condition } \\
\hline Pot size and soil & $10 \mathrm{~L}$, with potting soil & $7 \mathrm{~L}$, with sandy soil \\
\hline Initial nutrients $\left(\operatorname{pot}^{-1}\right)$ & $1.0 \mathrm{~g} \mathrm{~N}, 1.2 \mathrm{~g} \mathrm{P}_{2} \mathrm{O}_{5}$, and $2.1 \mathrm{~g} \mathrm{~K}_{2} \mathrm{O}$ & $0.40 \mathrm{~g} \mathrm{~N}$ \\
\hline Total additional nutrients $\left(\right.$ pot $\left.^{-1}\right)$ & $0.38 \mathrm{~g} \mathrm{~N}, 0.12 \mathrm{~g} \mathrm{P}_{2} \mathrm{O}_{5}$, and $0.40 \mathrm{~g} \mathrm{~K}_{2} \mathrm{O}$ & $0.50 \mathrm{~g} \mathrm{~N}, 0.50 \mathrm{~g} \mathrm{P}_{2} \mathrm{O}_{5}$ and $0.50 \mathrm{~g} \mathrm{~K}_{2} \mathrm{O}$ \\
\hline Temperature (day/night, ${ }^{\circ} \mathrm{C}$ ) & 21.4/17.0 & $28 / 23$ \\
\hline Relative humidity (\%) & ca 65 & ca 65 \\
\hline Photoperiod ( $\mathrm{h} \mathrm{d}^{-1}$ ) & 16 & 12 \\
\hline Supplementary lights on $\left(\mathrm{W} \mathrm{m}^{-2}\right)^{\mathrm{a}}$ & $\leq 150$ & $\leq 400$ \\
\hline Supplementary lights off $\left(\mathrm{W} \mathrm{m}^{-2}\right)^{\mathrm{b}}$ & $\geq 250$ & $\geq 500$ \\
\hline \multicolumn{3}{|l|}{ Measurement conditions } \\
\hline Position of measured leaves (from the bottom) & the 9th layer leaf & the 9th main-culm leaf \\
\hline$A-I_{\text {inc }}$ curves & 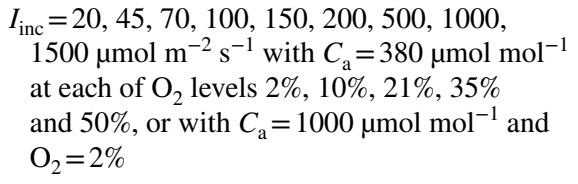 &  \\
\hline$A-C_{\mathrm{i}}$ curves & $\begin{array}{l}C_{\mathrm{a}}=50,65,80,100,150,200,380, \\
760,1000,1500 \mu \mathrm{mol} \mathrm{mol}^{-1} \text { with } \\
I_{\mathrm{inc}}=1000 \mu \mathrm{mol} \mathrm{m}^{-2} \mathrm{~s}^{-1} \text { at each of } \mathrm{O}_{2} \text { levels } \\
2 \%, 10 \%, 21 \%, 35 \% \text { and } 50 \%\end{array}$ & $\begin{array}{l}C_{\mathrm{a}}=50,65,80,100,150,200,380, \\
600,1000,1500 \mu \mathrm{mol} \mathrm{mol}^{-1} \text { with } \\
I_{\text {inc }}=1000 \mu \mathrm{mol} \mathrm{m}^{-2} \mathrm{~s}^{-1} \text { at each of } \mathrm{O}_{2} \text { levels } \\
2 \%, 10 \%, 21 \%, 35 \% \text { and } 50 \%\end{array}$ \\
\hline Leaf temperature $\left({ }^{\circ} \mathrm{C}\right)$ & 25 & 25 \\
\hline Leaf-to-air vapour pressure difference (kPa) & $0.7-1.5$ & $0.7-1.5$ \\
\hline
\end{tabular}

${ }^{\text {a }}$ Threshold solar incident light outside glasshouse when supplementary lights were switched on;

${ }^{\mathrm{b}}$ Threshold solar incident light outside glasshouse when supplementary lights were switched off 
(Monster, NL) was automatically switched on when the incident solar flux dropped below a threshold and off when it exceeded a threshold outside glasshouse. These threshold levels were set different for tomato and rice (Table 1), to mimic growth environments of the two species.

\section{Simultaneous gas exchange and chlorophyll fluorescence measurements}

We used the Li-Cor-6400XT open gas exchange system with an integrated fluorescence head enclosing a $2-\mathrm{cm}^{2}$ area (Li-Cor Inc, Lincoln-NE, USA). Young but fully expanded leaves of four replicated plants from staggered sowings were measured for incident irradiance $\left(I_{\text {inc }}\right)$ and $C_{\mathrm{a}}$ response curves in each species (Table 1).

Curves were measured at five $\mathrm{O}_{2}$ concentrations (Table 1). Additional light response curves were obtained at $1000 \mu \mathrm{mol} \mathrm{mol}^{-1} C_{\mathrm{a}}$ and $2 \% \mathrm{O}_{2}$ to establish nearly nonphotorespiratory conditions for calibration (see later). Gas from a cylinder containing a mixture of $\mathrm{O}_{2}$ and $\mathrm{N}_{2}$ was humidified and supplied via an overflow tube to the air inlet of the Li-Cor where $\mathrm{CO}_{2}$ was blended with the gas, and the IRGA was adjusted for $\mathrm{O}_{2}$ composition of the gas mixture according to the manufacturer's instructions. Based on pre-test measurements, we used 7-8 min for each step of an $A-I_{\text {inc }}$ curve, and 3-4 min for each step of an $A-C_{\mathrm{i}}$ curve, to reach a steady state. All $\mathrm{CO}_{2}$ exchange data were corrected for $\mathrm{CO}_{2}$ leakage into and out of the leaf cuvette, using measurements on boiled leaves (Flexas et al. 2007b), and then $C_{\mathrm{i}}$ was re-calculated.

When $A$ reached steady state at each light or $\mathrm{CO}_{2}$ step, steady-state fluorescence $\left(F_{\mathrm{s}}\right)$ was recorded. Maximum fluorescence $\left(F_{\mathrm{m}}^{\prime}\right)$ was measured using a $0.8 \mathrm{~s}$ light pulse of $>8000 \mu \mathrm{mol} \mathrm{m} \mathrm{m}^{-2} \mathrm{~s}^{-1}$, or the multiphase flash with each phase of $300 \mathrm{~ms}$ and ramp depth of $40 \%$ (Loriaux et al. 2013). The PSII operating efficiency $\left(\Delta F / F_{\mathrm{m}}^{\prime}\right)$ was set as $\left(F_{\mathrm{m}}^{\prime}-F_{\mathrm{s}}\right) / F_{\mathrm{m}}^{\prime}$ (Genty et al. 1989).

\section{Calibration and pre-determination of $\boldsymbol{R}_{\mathrm{d}}$ and Rubisco parameters}

Setting that $\Phi_{2}=\Delta F / F_{\mathrm{m}}^{\prime}, R_{\mathrm{d}}$ was estimated as the negative intercept of a linear regression of $A$ against $\left(I_{\text {inc }} \Phi_{2} / 4\right)$ using data of $A-I_{\text {inc }}$ curves within the electron transport-limited range for the nonphotorespiratory condition (Yin et al. 2009, 2011). The slope of the regression yields a calibration factor $(s)$, which lumps (1) absorptance by leaf photosynthetic pigments, (2) the factor for excitation partitioning to PSII, (3) basal forms of alternative electron transport, (4) any difference between real efficiency of PSII electron transport $\left(\Phi_{2}\right)$ and $\Delta F / F_{\mathrm{m}}^{\prime}$, and (5) possibly difference in chloroplast populations sampled by gas exchange and by chlorophyll fluorescence (van der Putten et al. 2018). The electron transport rate
$J$ can then be obtained as $J=s I_{\text {inc }}\left(\Delta F / F_{\mathrm{m}}^{\prime}\right)$ (Yin et al. 2009). Like other calibration methods, this procedure assumes that the calibration factor is the same for photorespiratory and nonphotorespiratory conditions, for which photosynthetic rates differ by a factor of $\left(C_{\mathrm{c}}-\Gamma_{*}\right) /\left(C_{\mathrm{c}}+2 \Gamma_{*}\right)$ (see Eqs. $\mathrm{S} 1.1$ and S1.3 in Supplementary Text S1; but with cautions from recent literature, Busch et al. 2018; Tcherkez and Limami 2019).

The parameter $\Gamma_{*}$ was calculated as $0.5 \mathrm{O}_{2} / S_{\mathrm{c} / \mathrm{o}}$, where $S_{\text {c/o }}$ is the relative $\mathrm{CO}_{2} / \mathrm{O}_{2}$ specificity of Rubisco (von Caemmerer et al. 1994). Values from in vitro measurements of Cousins et al. (2010) on $S_{\mathrm{c} / \mathrm{o}}\left(=3.022 \mathrm{mbar} \mu \mathrm{bar}^{-1}\right)$ and Michaelis-Menten coefficients of Rubisco for $\mathrm{CO}_{2}$ $\left(K_{\mathrm{mC}}=291 \mu \mathrm{bar}\right)$ and for $\mathrm{O}_{2}\left(K_{\mathrm{mO}}=194 \mathrm{mbar}\right)$ were taken, assuming that Rubisco kinetic constants are conserved among $\mathrm{C}_{3}$ species. This assumption was checked by in vivo estimates of $S_{\mathrm{c} / \mathrm{o}}$ from the lower parts of $A-C_{\mathrm{i}}$ curves of five $\mathrm{O}_{2}$ levels (see "Results").

\section{Model method}

After the above parameters were quantified, we first checked whether $g_{\mathrm{m} \text {,dif }}$ was variable based on the combined data of gas exchange and chlorophyll fluorescence. Using measured $A, C_{\mathrm{i}}$ and a tentative value for $m$ across its range $(0 \leq m \leq 1)$, $g_{\mathrm{m}, \mathrm{dif}}$ was calculated as

$g_{\mathrm{m}, \mathrm{dif}}=\frac{A+m\left(F+R_{\mathrm{d}}\right)}{C_{\mathrm{i}}-C_{\mathrm{c}}}$

where $F$ and $C_{\mathrm{c}}$ can be solved from the $A_{\mathrm{j}}$ equation of the FvCB model, see Eq. (S1.6) in Supplementary Text S1 and Eq. (S2.1) in Supplementary Text S2, respectively. Equation (4) was derived by Yin and Struik (2017, see their Eq. 19), in analogy to the variable J method of Harley et al. (1992; also see Eq. S2.2 in Supplementary Text S2).

The obtained $g_{\mathrm{m}, \text { dif }}$ responded to a change in both $C_{\mathrm{i}}$ and irradiance (see "Results"). Explaining these responses would need a separate study; to estimate $m$, here we adopted the generic phenomenological equation of Yin et al. (2009) to describe this response:

$g_{\mathrm{m}, \mathrm{dif}}=g_{\mathrm{mo}, \mathrm{dif}}+\delta\left(A+R_{\mathrm{d}}\right) /\left(C_{\mathrm{c}}-\Gamma_{*}\right)$

where $g_{\text {mo,dif }}$ and $\delta$ are parameters. If $\delta=0$, Eq. (5) becomes a constant $g_{\mathrm{m} \text {,dif }}$ mode $\left(=g_{\mathrm{mo}, \mathrm{dif}}\right)$. Any nonzero $\delta$ would predict a variable $g_{\mathrm{m} \text {,dif }}$ in response to $\mathrm{CO}_{2}, \mathrm{O}_{2}$ and irradiance levels, and if $g_{\text {mo,dif }}=0$, parameter $\delta$, as discussed later, represents the carboxylation: mesophyll resistance ratio. Equation (5) was combined with the FvCB and other equations to solve for $A$ (Supplementary Text $\mathrm{S} 1$, where reasons for using Eq. 5 are also explained). This results in an equation expressing $A$ as a function of $C_{\mathrm{i}}$ and other variables: 
$A=\left(-b \pm \sqrt{b^{2}-4 a c}\right) /(2 a)$

where

$$
\begin{aligned}
a= & x_{2}+\Gamma_{*}(1-m)+\delta\left(C_{\mathrm{i}}+x_{2}\right) \\
b= & m\left(R_{\mathrm{d}} x_{2}+\Gamma_{*} x_{1}\right)-\left[x_{2}+\Gamma_{*}(1-m)\right]\left(x_{1}-R_{\mathrm{d}}\right)-\left(C_{\mathrm{i}}+x_{2}\right) \\
& {\left[g_{\text {mo,dif }}\left(x_{2}+\Gamma_{*}\right)+\delta\left(x_{1}-R_{\mathrm{d}}\right)\right]-\delta\left[x_{1}\left(C_{\mathrm{i}}-\Gamma_{*}\right)-R_{\mathrm{d}}\left(C_{\mathrm{i}}+x_{2}\right)\right] } \\
& \\
c & =-m\left(R_{\mathrm{d}} x_{2}+\Gamma_{*} x_{1}\right)\left(x_{1}-R_{\mathrm{d}}\right) \\
& \quad+\left[g_{\text {mo,dif }}\left(x_{2}+\Gamma_{*}\right)+\delta\left(x_{1}-R_{\mathrm{d}}\right)\right] \\
& {\left[x_{1}\left(C_{\mathrm{i}}-\Gamma_{*}\right)-R_{\mathrm{d}}\left(C_{\mathrm{i}}+x_{2}\right)\right] }
\end{aligned}
$$

where $x_{1}=V_{\text {cmax }}$ (maximum carboxylation activity of Rubisco $)$ and $x_{2}=K_{\mathrm{mC}}\left(1+O_{2} / K_{\mathrm{mO}}\right)$ for the $A_{\mathrm{c}}$-limited conditions; $x_{1}=J / 4$ and $x_{2}=2 \Gamma_{*}$ for the $A_{\mathrm{j}}$-limited conditions, and for the $A_{\mathrm{p}}$-limited conditions: $x_{1}=3 T_{\mathrm{p}}$ (where $T_{\mathrm{p}}$ is the rate of triose phosphate export from the chloroplast) and $x_{2}=-(1+3 \alpha) \Gamma_{*}$ (where $\alpha$ is the fraction of glycolate carbon not returned to the chloroplast).

We found that the $\sqrt{b^{2}-4 a c}$ term of Eq. (6) should always take the - sign for either $A_{\mathrm{c}}$ - or $A_{\mathrm{j}}$-limited rate, but the solution for $A_{\mathrm{p}}$ is mathematically complicated if $\alpha>0$ (see Supplementary Text S4). Our data showed that $A$ often declined with increasing $C_{\mathrm{i}}$ within high $C_{\mathrm{i}}$ ranges (see "Results"), suggesting the limitation by triose phosphate utilization with $\alpha>0$ (Harley and Sharkey 1991). We conducted sensitivity analyses to choose a value of $\alpha$ although metabolic flux data (Abadie et al. 2018) suggest that its value might be small. We then used Eq. (6) to estimate four parameters: $m(0 \leq m \leq 1), \delta, V_{\text {cmax }}$ and $T_{\mathrm{p}}$, by a nonlinear fitting to all data of $A-C_{\mathrm{i}}$ and $A-I_{\mathrm{inc}}$ curves of the five $\mathrm{O}_{2}$ levels ( $g_{\text {mo,dif }}$ was set to zero, see "Results"). For that, $J$, as defined earlier as $I_{\text {inc }}\left(\Delta F / F_{\mathrm{m}}^{\prime}\right)$, were used as input. Our method assumed that $R_{\mathrm{d}}$ does not vary with $\left[\mathrm{O}_{2}\right]$, and was based on the expectation that neither $V_{\mathrm{cmax}}$ nor $T_{\mathrm{p}}$ varies with $\left[\mathrm{O}_{2}\right]$, as confirmed experimentally for $V_{\text {cmax }}$ (von Caemmerer et al. 1994). The fitting minimizes the sum of squared differences between estimated and measured $A$ values, using the GAUSS method in PROC NLIN (SAS Institute, NC, USA). SAS scripts can be obtained upon request.

Once $A$ was calculated from Eq. (6), $C_{\mathrm{c}}$ could be solved from Eq. (S2.1) in Supplementary Text S2. Then, $g_{\mathrm{m} \text {,dif }}$ was re-calculated from Eq. (4) using the estimated $m$ and measured $A$ and $C_{\mathrm{i}}$, where $x_{1}$ and $x_{2}$ terms were chosen according to whether the modelled $A$ was $A_{\mathrm{c}^{-}}, A_{\mathrm{j}}$ - or $A_{\mathrm{p}}$-limited. This showed $g_{\mathrm{m} \text {,dif }}$ in response to $\mathrm{CO}_{2}$, irradiance, and $\mathrm{O}_{2}$ levels.

With $g_{\mathrm{m}, \text { dif }}$ and other parameters, we calculated the fraction of (photo)respired $\mathrm{CO}_{2}$ being refixed $\left(f_{\text {refix }}\right)$, the fraction of (photo)respired $\mathrm{CO}_{2}$ being refixed within the mesophyll cells $\left(f_{\text {refix,cell }}\right)$, and the fraction of (photo)respired $\mathrm{CO}_{2}$ being refixed via IAS $\left(f_{\text {refix,ias }}\right)$, using Eqs. (S3.4), (S3.5) and (S3.6), respectively, in Supplementary Text S3. In these equations, $r_{\mathrm{sc}}$ is the stomatal resistance to $\mathrm{CO}_{2}$ diffusion (being 1.6 times measured stomatal resistance to water vapour), and $r_{\mathrm{cx}}$ is the carboxylation resistance (which is $\left(C_{\mathrm{c}}+x_{2}\right) / x_{1}$, von Caemmerer 2000). As discussed in Supplementary Text $\mathrm{S} 3$, these calculations need $\omega$ and $\lambda k$ as inputs. The estimate for $m$ was 0.3 for tomato and 0.0 for rice (see "Results"). For tomato, we measured $\omega(0.65)$ for leaves of the same age in the same cultivar "Growdena" (see Berghuijs et al. 2015) for calculating $\lambda k$, from $m=\omega(1-\lambda k)$. For rice, $\lambda k$ was set to 1.0 to agree with the estimate that $m=0$. In such a case, $\omega$ is not needed as Eqs. (S3.4) and (S3.5) become simplified as Eqs. (S3.3) and (S3.9) in Supplementary Text S3, respectively.

\section{Results}

Use of the five $\mathrm{O}_{2}$ levels generated diverse shapes of photosynthetic responses to irradiance and $\mathrm{CO}_{2}$ levels (Fig. 1). Our model approach, combined with data for $A$ (Fig. 1) and for $\Delta F / F_{\mathrm{m}}^{\prime}$ (Fig. S1), yielded an estimation of a set of parameters as described below.

\section{Estimated $R_{\mathrm{d}}$ and $s$}

Data of $A-I_{\text {inc }}$ curves within the range of $I_{\text {inc }} \leq 200 \mu \mathrm{mol} \mathrm{m}^{-2} \mathrm{~s}^{-1}$ showed that the relationship between $A$ and $\left(I_{\text {inc }} \Phi_{2} / 4\right)$ was linear for the conditions with a gas mixture of $2 \% \mathrm{O}_{2}$ with $1000 \mu \mathrm{mol} \mathrm{mol}^{-1} C_{\mathrm{a}}$ (Fig. 2), where $\Phi_{2}$ was set to be $\Delta F / F_{\mathrm{m}}^{\prime}$. The value of $R_{\mathrm{d}}$ estimated from this linear relationship was 1.2 (standard error or s.e. 0.1$) \mu \mathrm{mol}$ $\mathrm{m}^{-2} \mathrm{~s}^{-1}$ for tomato and 1.1 (s.e. 0.1$) \mu \mathrm{mol} \mathrm{m} \mathrm{m}^{-2} \mathrm{~s}^{-1}$ for rice. The slope of the $A-\left(I_{\text {inc }} \Phi_{2} / 4\right)$ linearity (i.e. calibration factor $s$ ) was 0.4570 (s.e. 0.0076 ) for tomato and 0.5488 (s.e. 0.0076 ) for rice. Values of $s$ were also re-estimated, together with other parameters, in fitting Eq. (6) to all data; but the reestimated $s$ remained the same, suggesting that we reached a nonphotorespiratory condition using the gas mixture.

The first few data points of the $A-C_{\mathrm{i}}$ curves were linear, and gross leaf photosynthesis values $A+R_{\mathrm{d}}$ were plotted versus $C_{\mathrm{i}}$ within this linear range. The intercept of this line with the $C_{\mathrm{i}}$-axis gives the estimate of the $C_{\mathrm{i}}$ based $\mathrm{CO}_{2}$ compensation point, commonly noted as $C_{\mathrm{i} *}$. The value of $C_{\mathrm{i}^{*}}$ increased linearly with increasing $\mathrm{O}_{2}$ levels (Fig. 3). Half of the reciprocal of this linear slope gives an in vivo estimate of $S_{\mathrm{c} / \mathrm{o}}$, which was $2.71 \mathrm{mbar}$ $\mu \mathrm{bar}^{-1}$ for tomato and $3.13 \mathrm{mbar} \mu \mathrm{bar}^{-1}$ for rice. Using the method of Yin et al. (2009) gave similar in vivo estimates of $S_{\text {c/o }}$ (results not shown). These values are close to $3.02 \mathrm{mbar} \mu \mathrm{bar}^{-1}$ measured in vitro for wheat by Cousins 
Fig. 1 Measured (points) and modelled (curves) net $\mathrm{CO}_{2}$ assimilation rate $A$ of tomato (filled circle, solid curves) and rice (open circle, dashed curves) as a function of incident irradiance $I_{\text {inc }}$ (left panels) and of intercellular $\mathrm{CO}_{2}$ concentration $C_{\mathrm{i}}$ (right panels) at different $\mathrm{O}_{2}$ percentages as shown in individual panels. Each point represents the mean of four replicated plants. The $A-I_{\text {inc }}$ curve under nonphotorespiratory (NPR) condition was obtained at $2 \% \mathrm{O}_{2}$ combined with ambient $\mathrm{CO}_{2}$ level of $1000 \mu \mathrm{mol} \mathrm{mol}^{-1}$. Curves were drawn from connecting two nearby values calculated by the model

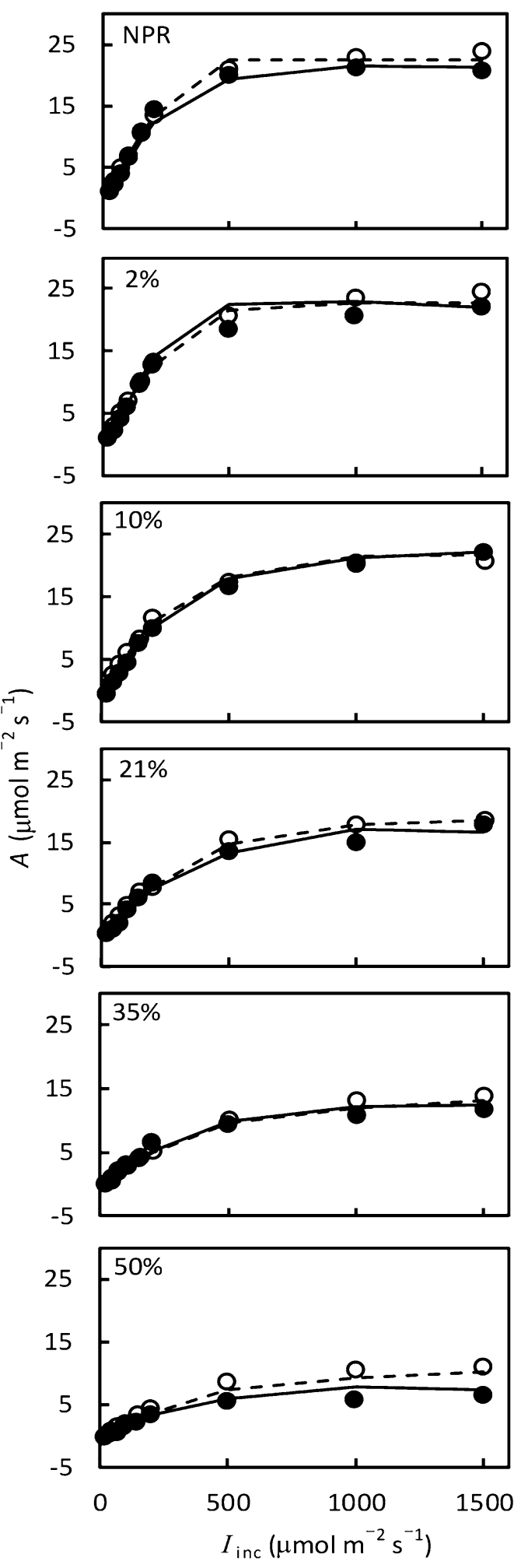


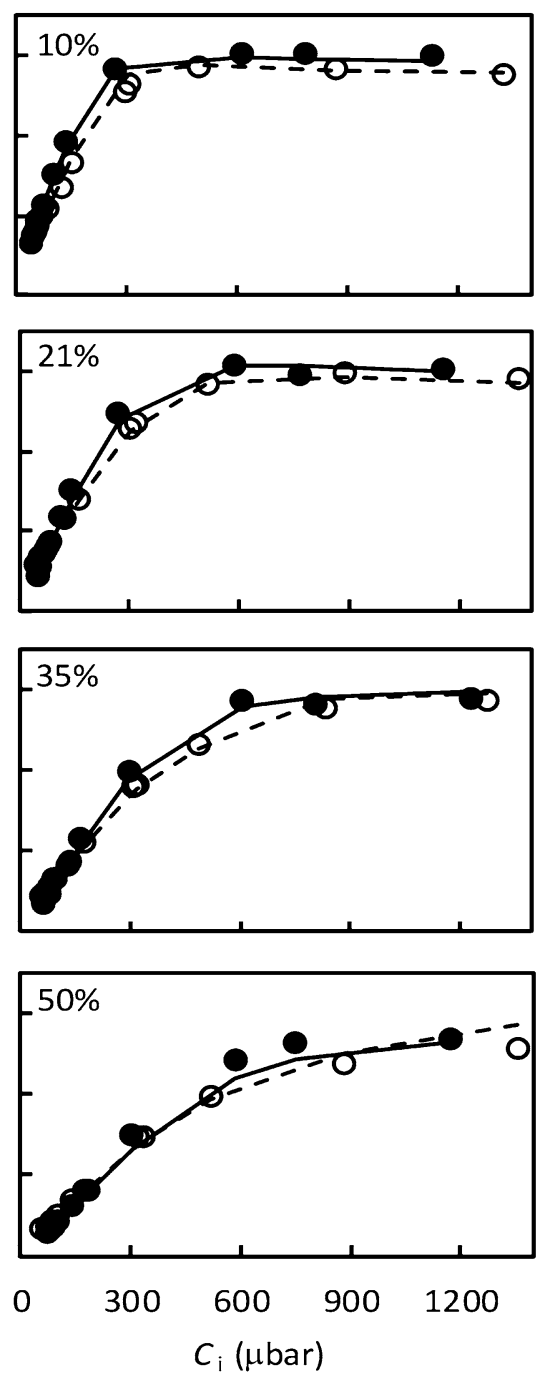

et al. (2010), confirming that $S_{\mathrm{c} / \mathrm{o}}$ is conserved among $\mathrm{C}_{3}$ species. We will use $3.02 \mathrm{mbar} \mu \mathrm{bar}^{-1}$ for further analysis (but see sensitivity analysis later).

\section{Dependence of $g_{\mathrm{m} \text {,dif }}$ on $\mathrm{CO}_{2}$ and irradiance level}

Equation (4) assuming an electron transport limitation, was applied to check the pattern of $g_{\mathrm{m}, \mathrm{dif}}$ across a range of $I_{\text {inc }}$ and $C_{\mathrm{i}}$ levels, by setting $m$ either to 0 (equivalent to the 

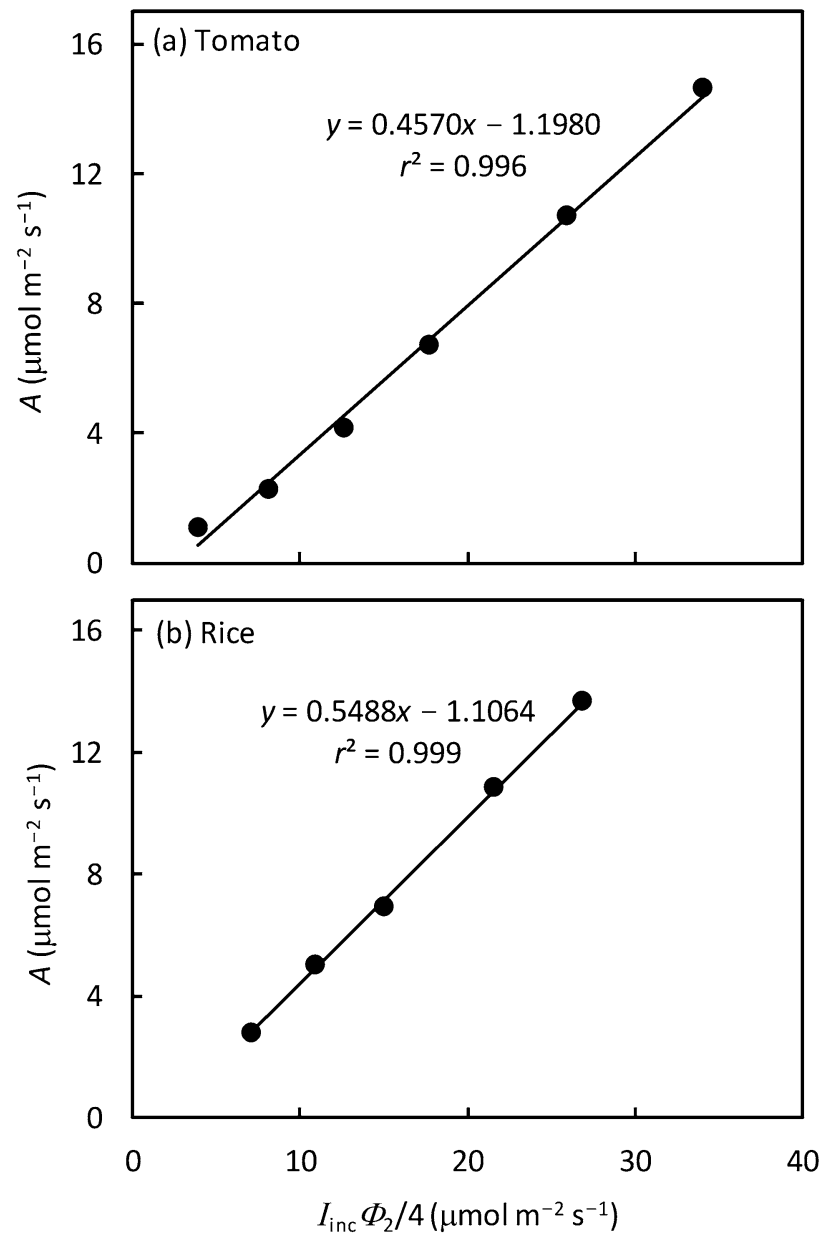

Fig. 2 Linear relationship between net $\mathrm{CO}_{2}$ assimilation rate $A$ and $I_{\text {inc }} \Phi_{2} / 4$, where $\Phi_{2}$ is set to be $\Delta F / F_{\mathrm{m}}^{\prime}$ and $I_{\text {inc }}$ is $\leq 200 \mu \mathrm{mol} \mathrm{m} \mathrm{m}^{-2} \mathrm{~s}^{-1}$ (each point represents the mean of measurements on leaves from four replicated plants), for nonphotorespiratory condition $\left(2 \% \mathrm{O}_{2}\right.$ combined with $C_{\mathrm{a}}=1000 \mu \mathrm{mol} \mathrm{mol}{ }^{-1}$ ). The intercept of regression lines gives an estimate of $-R_{\mathrm{d}}$ (see Yin et al., 2011), and the slope gives an estimate of the calibration factor $s$ for converting $\Delta F / F_{\mathrm{m}}^{\prime}$ into the linear electron transport rates (see the text)

variable J method of Harley et al. (1992) for $g_{\mathrm{m}, a \mathrm{pp}}$ ) or to a value between 0 and 1 . A similar response was obtained for various $\mathrm{O}_{2}$ levels, except for $2 \% \mathrm{O}_{2}$. At that oxygen concentration, Eq. (4), like the variable J method, cannot be reliably applied due to insufficient photorespiration (see Supplementary Text S2). Although the obtained $g_{\text {m,dif }}$ sometimes had unrealistic values largely due to unrealistic values of $C_{\mathrm{c}}$ (as often occurs when using the variable $\mathrm{J}$ method, see Yin and Struik 2009), an overall trend of $g_{\mathrm{m} \text {,dif }}$ in response to $I_{\text {inc }}$ and to $C_{\mathrm{i}}$ was obtained. An example of the response is shown in Fig. 4 for the case of $10 \% \mathrm{O}_{2}$ level for tomato. $g_{\mathrm{m} \text {,dif }}$ increased monotonically with increasing $I_{\text {inc }}$ (Fig. 4a), and decreased gradually with an increase in $C_{\mathrm{i}}$ (Fig. $4 \mathrm{~b}$ ). Changing $m$ did not change the response pattern, but only the absolute value of $g_{\mathrm{m} \text {,dif }}$, and a nonzero
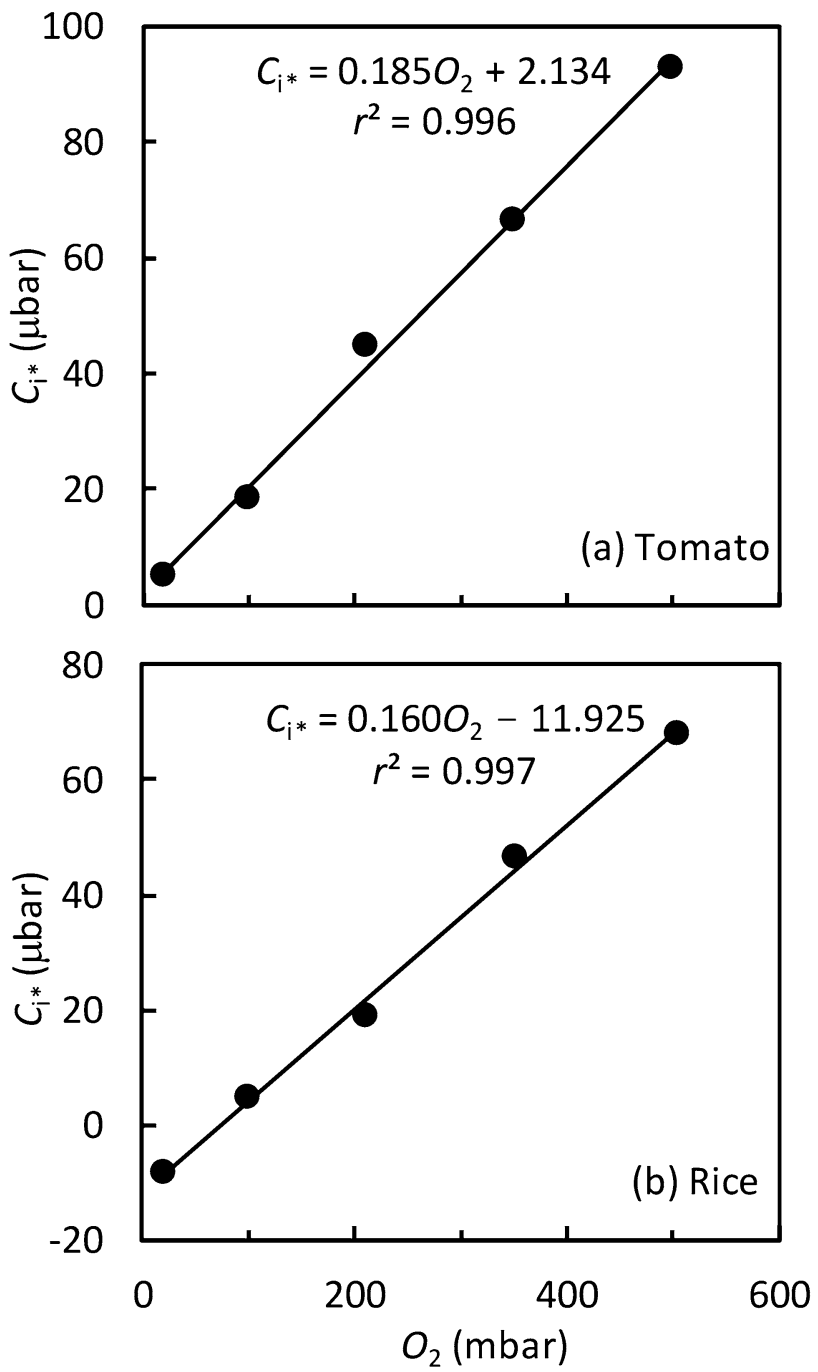

Fig. 3 Values of $\mathrm{CO}_{2}$ compensation point $C_{\mathrm{i}^{*}}$ [identified as the intercept at the $C_{\mathrm{i}}$-axis of the initial strictly linear part of leaf gross $\mathrm{CO}_{2}$ assimilation rate $\left(A+R_{\mathrm{d}}\right)$ versus $C_{\mathrm{i}}$ ] plotted as a function of the $\mathrm{O}_{2}$ levels, for tomato and rice leaves

$m$ resulted in higher $g_{\mathrm{m} \text {,dif }}$ than the value obtained from setting $m=0$ (Fig. 4).

\section{Estimates of parameters $\delta, m, V_{\mathrm{cmax}}$ and $T_{\mathrm{p}}$}

Equation (6) for describing $A$ was applied to estimate $g_{\text {mo,dif }}, \delta$ and $m$, using data of both $A-I_{\text {inc }}$ and $A-C_{\mathrm{i}}$ curves. The obtained $g_{\text {mo,dif }}$ did not differ significantly from zero $(p>0.05)$, which is supported by the result that the calculated $g_{\mathrm{m}, \text { dif }}$ by Eq. (4) at low $I_{\text {inc }}$ was close to zero (Fig. 4a). Also, model fit became worse if $\delta$ was fixed to zero than if $g_{\text {mo,dif }}$ was fixed to zero, supporting the variable $g_{\text {m,dif }}$ mode. Sensitivity analysis with respect to $\alpha$ suggested that a change within its relevant range had no impact on the estimates of parameters other than $T_{\mathrm{p}}$ (see below). We set $g_{\text {mo,dif }}$ to 



Fig. 4 Calculated $g_{\mathrm{m} \text {,app }}$ using the variable J method of Harley et al. (1992) (open square) or $g_{\mathrm{m} \text {,dif }}$ using Eq. (4) where parameter $m$ is set to 0.29 (filled circle), as a function of $\mathbf{a}$ incident irradiance $I_{\text {inc }}$ or $\mathbf{b}$ intercellular $\mathrm{CO}_{2}$ level $C_{\mathrm{i}}$, under the condition of $10 \% \mathrm{O}_{2}$ for tomato leaves. Points were obtained, based on the $A_{\mathrm{j}}$ part of the FvCB model, using measured $A$ and $J$ that was derived from chlorophyll fluorescence with the calibration as described in the text. The monotonically descending curve in panel (b) is drawn from values of the modelled $g_{\text {m,dif }}$ using the full FvCB model of three limited rates

zero, and $\alpha$ to 0.3 (Busch and Sage 2017), in the subsequent analysis.

Equation (6) describes well both $A-I_{\text {inc }}$ and $A-C_{\mathrm{i}}$ curves (Fig. 1), with an overall $R^{2}$ being $>0.99$ for either species (Table 2). Most of the data points $(>80 \%)$ were
$A_{\mathrm{j}}$-limited, indicating that chlorophyll fluorescence signals generally echoed gas exchange data since we calculated $J$ from chlorophyll fluorescence measurements as $s I_{\text {inc }}\left(\Delta F / F_{\mathrm{m}}^{\prime}\right)$. Only a few points at low $C_{\mathrm{i}}$ of $A-C_{\mathrm{i}}$ curves or at high $I_{\text {inc }}$ of $A-I_{\text {inc }}$ curves were $A_{\mathrm{c}}$-limited, and a few points at high $C_{\mathrm{i}}$ of $A-C_{\mathrm{i}}$ curves under low $\mathrm{O}_{2}$ conditions were $A_{\mathrm{p}}$-limited. The estimated $m$ was ca 0.3 for tomato but was 0.0 for rice (Table 2). The estimated $\delta$ was also higher for tomato (1.4) than for rice (1.0) (Table 2). Other parameter values were similar for the two species: 113.7 and $111.0 \mu \mathrm{mol} \mathrm{m} \mathrm{m}^{-2} \mathrm{~s}^{-1}$ for $V_{\text {cmax }}$, and 8.3 and $7.8 \mu \mathrm{mol} \mathrm{m} \mathrm{m}^{-2} \mathrm{~s}^{-1}$ for $T_{\mathrm{p}}$, for tomato and rice, respectively.

\section{Sensitivity analysis}

Given that any uncertainty in estimated $s$ and $R_{\mathrm{d}}$ and in other parameters $\left(S_{\mathrm{c} / \mathrm{o}}, K_{\mathrm{mC}}, K_{\mathrm{mO}}\right.$ and $\left.\alpha\right)$ may have an impact on the major estimated parameters ( $m$ and $\delta$ in this study), we carried out sensitivity analyses. The estimation of $\delta$ and $m$ was very sensitive to $s$ and $S_{\text {c/o }}$, and less sensitive to $R_{\mathrm{d}}$ (Fig. S2), but virtually insensitive to $K_{\mathrm{mC}}, K_{\mathrm{mO}}$ and $\alpha$ (results not shown). Both $\delta$ and $m$ decreased monotonically with increasing $s$ (Fig. S2a). The estimate of $\delta$ decreased with increasing $S_{\mathrm{c} / \mathrm{o}}$, whereas that of $m$ changed in an opposite direction (Fig. S2b). The obtained response of $\delta$ (the parameter in Eq. (5) on mesophyll conductance) to both $S_{\mathrm{c} / \mathrm{o}}$ and $s$ is expected in the same way as $g_{\mathrm{m} \text {,app }}$ responds to these parameters (Harley et al. 1992). The opposite response of $m$ to $S_{\mathrm{c} / \mathrm{o}}$ and $s$ is probably because photorespiration, i.e. the $F$ term in Eq. (3), which is relevant to determining $m$, has an opposite response to $S_{\mathrm{c} / \mathrm{o}}$ and $s$. As $R_{\mathrm{d}}$ has the same effect as the $F$ term has (see Eq. 3), the estimated $m$ decreased with increasing $R_{\mathrm{d}}$, whereas $\delta$ changed in an opposite direction (Fig. S2c). As expected, any sensitivity to $K_{\mathrm{mC}}$ and $K_{\mathrm{mO}}$ occurred with the estimated $V_{\text {cmax }}$, whereas a sensitivity to $\alpha$ occurred with $T_{\mathrm{p}}$ (results not shown).
Table 2 Estimates (standard errors in brackets) of two major parameters $(\delta$ and $m)$, and $V_{\text {cmax }}$ and $T_{\mathrm{p}}$, from fitting Eq. (6) to irradiance- and $\mathrm{CO}_{2}$ response curves of five $\mathrm{O}_{2}$ levels for leaves of tomato and rice

\begin{tabular}{|c|c|c|c|}
\hline \multirow[t]{2}{*}{ Parameter } & \multirow[t]{2}{*}{ Unit } & \multicolumn{2}{|l|}{ Estimates } \\
\hline & & Tomato & Rice \\
\hline$\delta$ (a coefficient defining variations in $g_{\mathrm{m}, \mathrm{dif}}$ ) & - & $1.41(0.09)$ & $1.03(0.05)$ \\
\hline$m$ (lumped anatomical-feature parameter) & - & $0.29(0.07)$ & 0.00 \\
\hline$V_{\text {cmax }}\left(\right.$ maximum rate of Rubisco activity ${ }^{a}$ & $\mu \mathrm{mol} \mathrm{m} \mathrm{m}^{-2} \mathrm{~s}^{-1}$ & $113.70(3.51)$ & $111.0(6.44)$ \\
\hline$T_{\mathrm{p}}$ (rate of triose phosphate utilization) ${ }^{\mathrm{b}}$ & $\mu \mathrm{mol} \mathrm{m} \mathrm{m}^{-2} \mathrm{~s}^{-1}$ & $8.31(0.11)$ & $7.81(0.06)$ \\
\hline$R^{2}$ & - & 0.992 & 0.993 \\
\hline
\end{tabular}

${ }^{\text {a }}$ Sensitivity analysis showed that only the estimate of $V_{\mathrm{cmax}}$ depends on values of $K_{\mathrm{mC}}$ and $K_{\mathrm{mO}}$ (see text); here $V_{\text {cmax }}$ was estimated using $K_{\mathrm{mC}}=291 \mu$ bar and $K_{\mathrm{mO}}=194 \mathrm{mbar}$ (Cousins et al. 2010)

${ }^{\mathrm{b}}$ Sensitivity analysis showed that only the estimate of $T_{\mathrm{p}}$ depends on the value of $\alpha$ (see text); here $T_{\mathrm{p}}$ was estimated assuming that $\alpha=0.3$ (Busch and Sage 2017) 


\section{Calculated fractions for re-assimilation of (photo) respired $\mathrm{CO}_{2}$}

The calculated fractions of (photo)respired $\mathrm{CO}_{2}$ being refixed, using Eqs. (S3.4-S3.6) in Supplementary Text S3, are shown in Fig. 5, using the result at $21 \% \mathrm{O}_{2}$ as the example. The trends were similar for $\mathrm{O}_{2}$ levels above $2 \%$. Except for very low $I_{\mathrm{inc}}$ or $C_{\mathrm{i}}$ levels, the refixed fractions were quite consistent over a wide range of conditions. $f_{\text {refix,cell }}$ was lower in tomato (0.25) than in rice (0.49) (Fig. 5), largely due to the fact that the estimated $m$ was 0.3 for tomato but 0.0 for rice (Table 2). In contrast, $f_{\text {refix,ias }}$ was higher in tomato than in rice. As a result, the total re-fixation fraction $f_{\text {refix }}$ was comparable for the two species, i.e. up to ca 0.6.

\section{Responses of stomatal and mesophyll conductance to $\mathrm{O}_{2}$}

Except for a few cases, $g_{\text {sc }}$ generally decreased with increasing $\left[\mathrm{O}_{2}\right]$, and was lower in tomato than in rice (Fig. 6). The calculated value of $g_{\mathrm{m} \text {,dif }}$ also decreased with increasing $\left[\mathrm{O}_{2}\right]$, except for very high $\mathrm{CO}_{2}$ conditions which lowered $g_{\mathrm{m} \text {,dif }}$ to the extent that the $\mathrm{O}_{2}$ response of $g_{\mathrm{m} \text {,dif }}$ was no longer significant (Fig. 6d,j). $g_{\mathrm{m}, \mathrm{dif}}$ was higher in tomato than in rice.

\section{Discussion}

\section{Analysing mesophyll resistance}

Compared with the $\mathrm{CO}_{2}$ flux coming from IAS, (photo) respired $\mathrm{CO}_{2}$ experiences different resistances. This suggests the need to dissect $r_{\mathrm{m} \text {,dif }}$ into sub-components. Anatomical measurements can partition mesophyll resistance into individual sub-components (Peguero-Pina et al. 2012; Tosens et al. 2012a, b; Tomas et al. 2013; Carriquí et al. 2019). The calculation of these sub-components relies on many assumed diffusion or permeability coefficients that are uncertain (Berghuijs et al. 2015). Furthermore, this approach does not quantify the effect of the arrangement of mitochondria and chloroplasts on the intracellular $\mathrm{CO}_{2}$ diffusion.

In line with anatomical measurements, Eq. (2) dissects $r_{\mathrm{m}, \text { dif }}$ into two sub-components $r_{\mathrm{wp}}$ and $r_{\mathrm{ch}}$ (Tholen et al. 2012). Oxygen isotope techniques may estimate $r_{\mathrm{wp}}$ based on certain assumptions (Barbour 2017), but so far have been explored to separate $r_{\mathrm{wp}}$ and $r_{\mathrm{ch}}$ within the framework of the classical $g_{\mathrm{m}}$ model, Eq. (1) (Barbour et al. 2016b). Equations (1) and (2) both underrepresent the intracellular arrangements of organelles. In contrast, the model of Yin and Struik (2017), Eq. (3), has a factor lumping (i) the
Fig. 5 Calculated fractions of total re-assimilation (filled circle, $\left.f_{\text {refix }}\right)$, of re-assimilation within mesophyll cells (open square, $\left.f_{\text {refix,cell }}\right)$, and of reassimilation via the intercellular air spaces (open triangle, $\left.f_{\text {refix,ias }}\right)$ at different incident irradiance $(\mathbf{a}, \mathbf{c})$ or intercellular $\mathrm{CO}_{2}(\mathbf{b}, \mathbf{d})$ levels, in leaves of tomato $(\mathbf{a}, \mathbf{b})$ and rice $(\mathbf{c}, \mathbf{d})$, when the $\mathrm{O}_{2}$ level was $21 \%$. The horizontal dashed line represents the calculated $f_{\text {refix,cell }}$ using the model predicted $A$ values. In the calculation for tomato, we used the value of $\omega$ (the proportion of $r_{\mathrm{ch}}$ in total $\left.r_{\mathrm{m}, \mathrm{dif}}\right)$ of 0.65 that we measured, as reported by Berghuijs et al.

(2015, see the text)

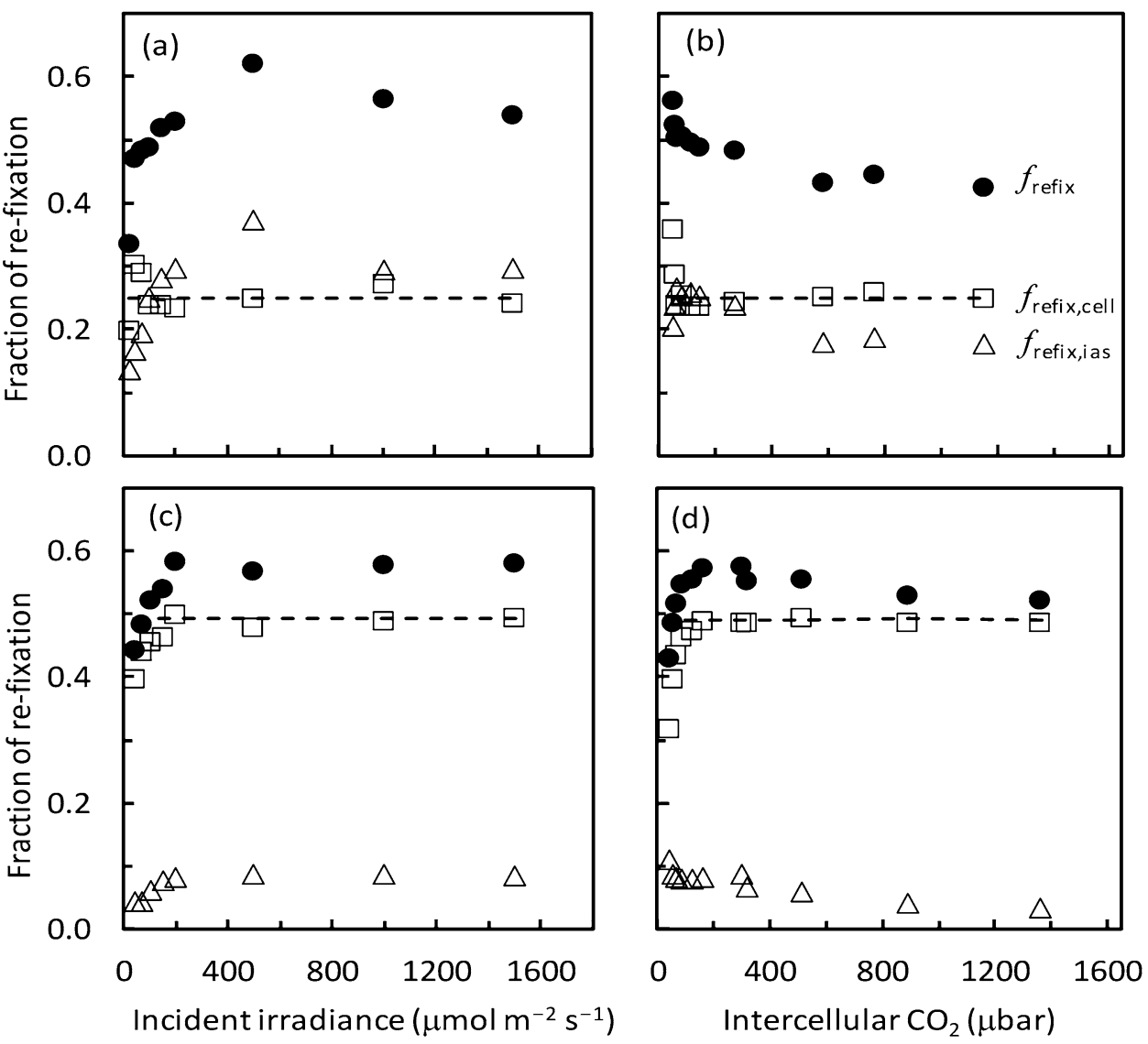


High

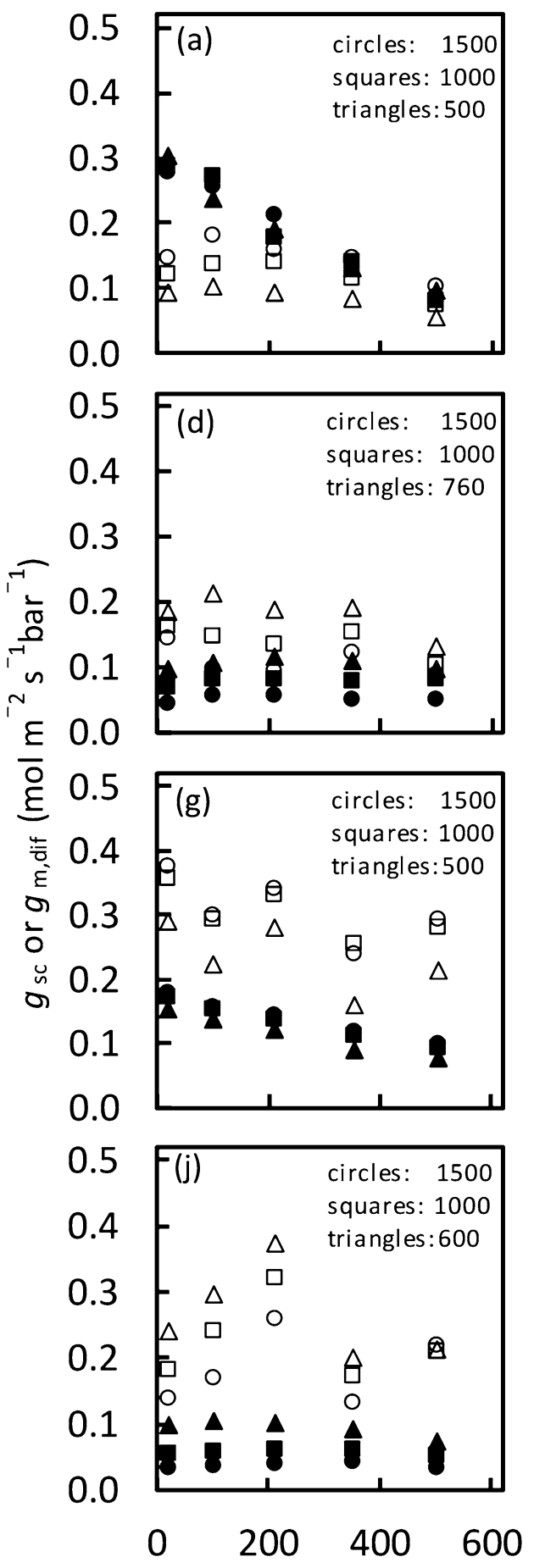

Medium
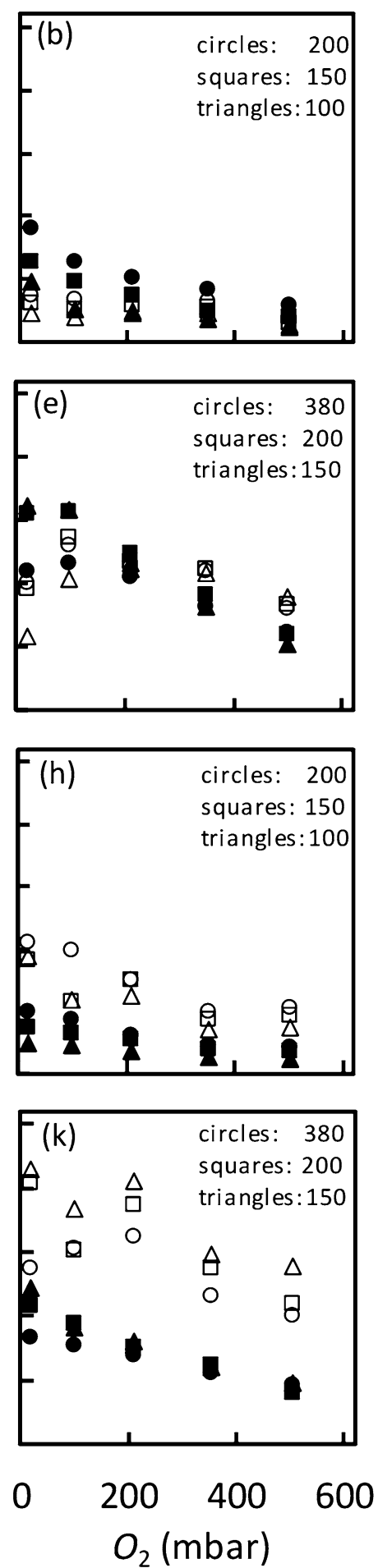

Low

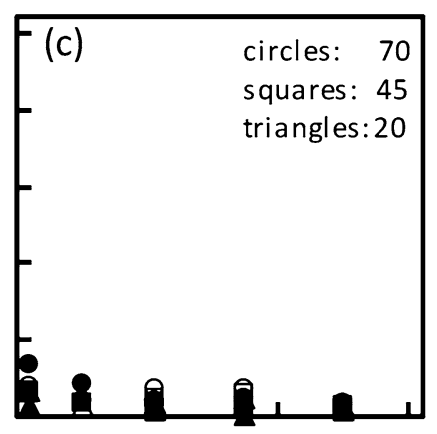

$I_{\text {inc }}$

$C_{\mathrm{a}}$

triangles: 65,50
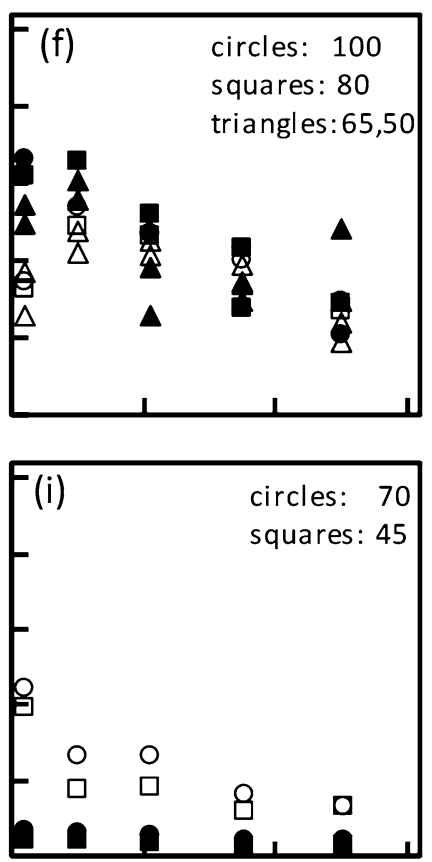

$I_{\text {inc }}$

$C_{\mathrm{a}}$

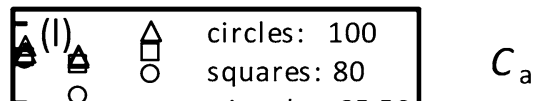

Fig. 6 Stomatal conductance for $\mathrm{CO}_{2}$ diffusion $g_{\mathrm{sc}}$ (open symbols) and mesophyll conductance $g_{\mathrm{m} \text {,dif }}$ (closed symbols) of tomato (a-f) and rice (g-l) leaves in response to $\mathrm{O}_{2}$ level, at high (left panels), medium (middle panels) and low (right panels) $I_{\text {inc }}$ levels $(\mathbf{a}-\mathbf{c}, \mathbf{g}-\mathbf{i})$

or $C_{\mathrm{a}}$ levels $(\mathbf{d}-\mathbf{f}, \mathbf{j}-\mathbf{l})$. Values of $I_{\text {inc }}$ or $C_{\mathrm{a}}$ are shown at each corresponding panels, where units of $I_{\mathrm{inc}}$ and $C_{\mathrm{a}}$ are $\mu \mathrm{mol} \mathrm{m} \mathrm{m}^{-2} \mathrm{~s}^{-1}$ and $\mu \mathrm{mol} \mathrm{mol}{ }^{-1}$, respectively 
$r_{\mathrm{ch}}: r_{\mathrm{m}, \mathrm{dif}}$ ratio $(\omega)$, (ii) the fraction of (photo)respired $\mathrm{CO}_{2}$ that are released in the inner cytosol $(\lambda)$, and (iii) $k$, the factor for the change in $\lambda$ as a result of the chloroplast gaps. The factor $k$ is particularly hard to assess. Since $\omega, \lambda$ and $k$ lump as such that $m=\omega(1-\lambda k)$, Eq. (3) provides an approach by exploring nondestructive gas exchange and chlorophyll fluorescence measurements under different levels of $\mathrm{O}_{2}$ that created large variations in photorespiration. Instead of estimating individual resistances, our nonlinear fitting approach estimates $r_{\mathrm{m} \text {,dif }}$ as a whole, as well as the $m$ factor. Common nonlinear procedures, typically by fitting $A-C_{\mathrm{i}}$ curves, estimate four or even more parameters of the FvCB model, such as $V_{\text {cmax }}, J, T_{\mathrm{p}}$, and $g_{\mathrm{m}}$ (e.g. Sharkey et al. 2007). In our method, $J$ was measured from chlorophyll fluorescence. Despite a wide range of $\mathrm{O}_{2}$ levels exploited, we restricted the number of estimated parameters to four from Eq. (6)-based nonlinear fitting. All four were reliably estimated for both species with small standard errors (Table 2).

Our approach is still a simplified representation of complex diffusion pathways. Some respiratory flux may originate in the chloroplasts, in cytosol, and in the heterotrophic tissues such as epidermis, vasculature, and bundle sheath (Tcherkez et al. 2017). These components of $R_{\mathrm{d}}$ could be incorporated as additional terms into the $C_{\mathrm{i}}-C_{\mathrm{c}}$ gradient equation, Eq. (S1.7) in Supplementary Text S1. However, they are ignored here as fractions of these components in $R_{\mathrm{d}}$ are generally unknown. There may also be some activity of phosphoenolpyruvate carboxylase $\left(V_{\text {pepc }}\right)$ in cytosol (Douthe et al. 2012; Abadie and Tcherkez 2019), which would counteract the effect of $\left(F+R_{\mathrm{d}}\right)$ on $g_{\mathrm{m} \text {,app }}$. But our procedure of estimating $R_{\mathrm{d}}$ may have accounted for this, i.e. the estimated $R_{\mathrm{d}}$ represents the net rate of true $R_{\mathrm{d}}$ minus $V_{\text {pepc }}$. Tholen et al. (2012) showed that small amounts of $V_{\text {pepc }}$ have little impact on $g_{\mathrm{m} \text {,app }}$.

\section{Variation of $g_{\mathrm{m} \text {, dif }}$ with $\mathrm{CO}_{2}$, irradiance and $\mathrm{O}_{2}$ levels}

Reports using chlorophyll fluorescence data consistently showed that $g_{\mathrm{m} \text {,app }}$ initially increases and then decreases with increasing $C_{\mathrm{i}}$ and increases monotonically with increasing $I_{\text {inc }}$ (e.g. Flexas et al. 2007a; Yin et al. 2009). Similar results for $g_{\mathrm{m} \text {,app }}$ in response to $C_{\mathrm{i}}$ (Vrábl et al. 2009; Tazoe et al. 2011) and to $I_{\text {inc }}$ (Douthe et al. 2012) were sometimes reported, using the carbon isotope discrimination method. No change in anatomical arrangements was observed that could explain the variable $g_{\text {m,app }}$ (Carriquí et al. 2019). Gu and Sun (2014) showed that the reported response of $g_{\mathrm{m}, \text { app }}$ to a change in $\mathrm{CO}_{2}$ or in $I_{\text {inc }}$ may be due to the artefact of errors in experimental measurements. Although resolving experimental uncertainties is urgently needed, consistent variations of $g_{\mathrm{m} \text {,app }}$ cannot be ascribed only to experimental errors because responses due to random errors would be irregular and inconsistent among various reports. Théroux-Rancourt and Gilbert (2017) demonstrated that changing patterns of light penetration within the leaf 3D-structure leads to different contributions of each cell layer to bulk-leaf mesophyll conductance, resulting in an apparent response of the bulkleaf $g_{\mathrm{m} \text {,app }}$ to light intensity. However, their theory cannot explain the response of $g_{\mathrm{m} \text {,app }}$ to $C_{\mathrm{i}}$.

Most results using the variable $\mathrm{J}$ method of Harley et al. (1992) showed that within a low $C_{\mathrm{i}}$ range, $g_{\mathrm{m} \text {,app }}$ typically decreases with decreasing $C_{\mathrm{i}}$ (e.g. Flexas et al. 2007a; Vrábl et al. 2009; Yin et al. 2009; Fig. 4b). Tholen et al. (2012) also noted a decrease of $g_{\mathrm{m} \text {,app }}$ with increasing $\mathrm{O}_{2}$ level. Tholen et al. (2012) explained these responses to $C_{\mathrm{i}}$ and $\mathrm{O}_{2}$ as a consequence of the fact that $g_{\mathrm{m} \text {,app }}$ as an apparent parameter decreases with an increase in the $\left(F+R_{\mathrm{d}}\right) / A$ ratio. If this is the only explanation of variable $g_{\mathrm{m}, \text { app }}$, one would expect that $g_{\mathrm{m} \text {,dif }}$ would be independent of $C_{\mathrm{i}}$ because Eq. (4) for $g_{\mathrm{m} \text {,dif }}$ already accounts for the $\left(F+R_{\mathrm{d}}\right) / A$ ratio. However, $g_{\mathrm{m} \text {,dif }}$ still declined with decreasing $C_{\mathrm{i}}$ within its low range, albeit to a lesser extent (Fig. 4b). In fact, within the low $C_{\mathrm{i}}$ range, $A$ is limited by Rubisco activity; so, as noted by Yin et al. (2009), using the variable J method or Eq. (4) assuming an electron transport limitation results in an artefactual decline of estimated $g_{\mathrm{m}}$ because the occurrence of additional alternative electron transport is wrongly attributed to the mesophyll diffusional limitation. This assertion was supported by the result that the decrease of $g_{\text {m,dif }}$ with decreasing $C_{\mathrm{i}}$ within the low $C_{\mathrm{i}}$ range was no longer obtained once $g_{\mathrm{m} \text {,dif }}$ was calculated from the full FvCB model (Fig. 4b). This suggests that the decrease of $g_{\text {m,app }}$ with decreasing $C_{\mathrm{i}}$ is explained more by the occurrence of alternative electron transport than by the theory of Tholen et al. Anyway, the theory does not explain the decreases of $g_{\mathrm{m} \text {,app }}$ with increasing $C_{\mathrm{i}}$ within its high range, or with decreasing $I_{\text {inc }}$, or with lowering temperature as reported previously (Bernacchi et al. 2002; Warren and Dreyer 2006; Yamori et al. 2006; Scafaro et al. 2011; Evans and von Caemmerer 2013).

We found that $g_{\mathrm{m} \text {,dif }}$ increased with $I_{\text {inc }}$ (Fig. 4a). This increase continued within the high $I_{\text {inc }}$ range, where some additional alternative electron transport is also expected, suggesting that the increase of $g_{\mathrm{m} \text {,dif }}$ with $I_{\text {inc }}$ overrode any artefactual decline caused by alternative electron fluxes. Also, $g_{\mathrm{m} \text {,dif }}$ decreased with increasing $\mathrm{O}_{2}$ (Fig. 6), in the same direction as the $\mathrm{O}_{2}$ response of $g_{\text {m,app }}$ reported by Tholen et al. (2012). Literature on $\mathrm{O}_{2}$ responses of diffusional conductance is scarce (Farquhar and Wong 1984; Buckley et al. 2003). Our data showed that both $g_{\mathrm{sc}}$ and $g_{\mathrm{m}, \mathrm{dif}}$ generally declined with increasing $\mathrm{O}_{2}$. So, $g_{\mathrm{m} \text {,dif }}$ is variable, in response to $C_{\mathrm{i}}, I_{\mathrm{inc}}$, and $\mathrm{O}_{2}$, in a similar pattern as $g_{\mathrm{sc}}$ responds to these variables (e.g. Morison and Gifford 1983; Farquhar and Wong 1984; Buckley et al. 2003).

The identified variable $g_{\mathrm{m} \text {,dif }}$ was based on the assumption that $m(=\omega(1-\lambda k))$ is constant, independent of short-term changes (within 3-8 min) in irradiance or $\left[\mathrm{CO}_{2}\right]$. This is 
supported by Carriquí et al. (2019), who reported that anatomical parameters determining $\omega$ and $k$ hardly vary with short-term changes in irradiance or $\left[\mathrm{CO}_{2}\right]$. Chloroplasts and mitochondria in some plants may move under varying light, but they always colocalize (Islam et al. 2009), suggesting that $\lambda$ also hardly varies. We are unable to find evidences supporting quantitative changes that $m$ or its components must have to obtain invariable $g_{\mathrm{m} \text {,dif }}$ with irradiance, $\left[\mathrm{CO}_{2}\right]$ and $\left[\mathrm{O}_{2}\right]$.

$g_{\mathrm{m} \text {,dif }}$ defined here is still a bulk-leaf trait. Like bulk-leaf $g_{\mathrm{m}, \mathrm{app}}$, it may not represent intrinsic transport properties. Also, our result on the variable $g_{\mathrm{m} \text {,dif }}$ is subject to experimental confirmation by other methods. If proven true, future studies are needed to examine if the variable $g_{\mathrm{m} \text {,dif }}$ can emerge from fluxes and concentrations across the real 3D-structure of leaves, as well as in relation to membrane permeability and other properties. Here we only describe the response from bulk-leaf equations themselves. $g_{\mathrm{m}, \mathrm{dif}}$ can be formulated from Eq. (4) and $A=V-F-R_{\mathrm{d}}$ (where $V$ is the carboxylation rate) as

$g_{\mathrm{m}, \mathrm{dif}}=\frac{V-(1-m)\left(F+R_{\mathrm{d}}\right)}{C_{\mathrm{i}}\left(1-C_{\mathrm{c}}: C_{\mathrm{i}}\right)}$

When $I_{\text {inc }}$ increases, only the numerator increases significantly; so Eq. (7) predicts that $g_{\mathrm{m} \text {,dif }}$ increases with increasing $I_{\text {inc. }}$. If the $\mathrm{CO}_{2}$ gradient from $C_{\mathrm{i}}$ and $C_{\mathrm{c}}$ is regulated such that the $C_{\mathrm{c}}: C_{\mathrm{i}}$ ratio is roughly constant for a given $\mathrm{O}_{2}$ level (results not shown), Eq. (7) also predicts that $g_{\mathrm{m} \text {,dif }}$ will decrease monotonically with $C_{\mathrm{i}}$ because according to the FvCB model, the $V$ increment per $C_{\mathrm{i}}$ increment decreases with increasing $C_{\mathrm{i}}$. Finally, the $F$ term increases when $\mathrm{O}_{2}$ increases; as a result, Eq. (7) predicts that $g_{\mathrm{m} \text {,dif }}$ decreased with increasing $\mathrm{O}_{2}$ (Fig. 6).

\section{Interpretation of the model and estimated parameter values}

Our method is based on Eq. (3), the equation summarized by Yin and Struik (2017) from considering six possible scenarios for the intracellular organelle arrangement. Recently, Ubierna et al. (2019) came up with the same model but formulated $g_{\mathrm{m} \text {,app }}$ in a Michaelis-Menten-like equation, i.e. $g_{\mathrm{m}, \text { app }}=A \cdot g_{\mathrm{m}, \mathrm{dif}} /\left[A+m\left(F+R_{\mathrm{d}}\right)\right]$ (see their Eq. 15 ; note that $g_{\mathrm{m} \text {,app }}$ was written as $g_{\mathrm{m}}$ in their notations). The maximum value of $g_{\text {mapp }}$ is $g_{\text {m,dif }}$, while the Michaelis-Menten constant " $K_{\mathrm{m}}$ " is $m\left(F+R_{\mathrm{d}}\right)$. For the case of tomato where $m=0.3$ and $R_{\mathrm{d}}=1.2$, the " $K_{\mathrm{m}}$ " occurs at $A \approx 2.0 \mu \mathrm{mol} \mathrm{m}{ }^{-2} \mathrm{~s}^{-1}$ for the ambient $\mathrm{O}_{2}$ condition. This suggests that $g_{\mathrm{m} \text {,app }}$ and $g_{\mathrm{m} \text {,dif }}$ only differ significantly when $A$ is low, which our results (Fig. 4) confirmed.

In view of the variation of $g_{\mathrm{m} \text {,dif }}$ shown in Fig. 4, we adopted Eq. (5), which accommodates either constant or variable $g_{\mathrm{m} \text {,dif }}$ in relation to $C_{\mathrm{i}}, I_{\mathrm{inc}}$ and $\mathrm{O}_{2}$ levels. Although the equation is phenomenological and has an a priori assumption that $g_{\mathrm{m}, \text { dif }}$ grows with relative carboxylation and the estimates of its parameters are expectedly sensitive to the pre-input values of $s, S_{\mathrm{c} / \mathrm{o}}$ and $R_{\mathrm{d}}$ (Fig. S2), the model generated useful insights.

Our results supported no constant $g_{\mathrm{m}, \mathrm{dif}}$, but a variable $g_{\mathrm{m} \text {,dif }}$ with parameter $\delta$ being 1.0 for rice and 1.4 for tomato (Table 2). Equation (5) with $g_{\text {mo,dif }}=0$ for our variable $g_{\mathrm{m}, \text { dif }}$ mode can be rewritten to $r_{\mathrm{m}, \text { dif }}=\left(C_{\mathrm{c}}-\Gamma_{*}\right) /\left[\delta\left(A+R_{\mathrm{d}}\right)\right]$. As $\left(A+R_{\mathrm{d}}\right)$ can be calculated from the FvCB model as $\left(C_{\mathrm{c}}-\Gamma_{*}\right) x_{1} /\left(C_{\mathrm{c}}+x_{2}\right)$, the above equation becomes $r_{\text {m,dif }}=\left(C_{\mathrm{c}}+x_{2}\right) /\left(\delta x_{1}\right)$. As $\left(C_{\mathrm{c}}+x_{2}\right) / x_{1}$ is defined as carboxylation resistance $r_{\mathrm{cx}}$ (von Caemmerer 2000), it follows that

$\delta=r_{\mathrm{cx}} / r_{\mathrm{m}, \mathrm{dif}}$.

Thus, parameter $\delta$ of Eq. (5) has a meaning, representing the carboxylation: mesophyll resistance ratio. Our estimates for $\delta$ (Table 2) suggest that $r_{\mathrm{cx}}$ and $r_{\mathrm{m} \text {,dif }}$ had similar values in rice leaves, whereas $r_{\mathrm{cx}}$ was ca $40 \%$ higher than $r_{\mathrm{m} \text {,dif }}$ in tomato leaves.

Our estimate of the factor $m$ was ca 0.3 for tomato and 0.0 for rice (Table 2). Thus, using Eq. (1), which is the special case of the generalized model when $m=0$, actually suits for rice leaves but does not work for tomato leaves when $\left(F+R_{\mathrm{d}}\right) / A$ is high. As stated in Introduction, the classical model works well if mitochondria are located exclusively in the inner cytosol $(\lambda=1)$ and chloroplasts cover fully the mesophyll periphery that $k=1$. Sage and Sage (2009) and Busch et al. (2013) showed that compared with other species, in rice leaves, there are stromules that effectively extend chloroplast coverage of the cell periphery and mitochondria locate in the cell interior and are intimately associated with chloroplasts/stromules. These features engender such a structure as if (photo)respired $\mathrm{CO}_{2}$ is released in the same compartment where RuBP carboxylation occurs. This is the case when Eq. (1) works well. Therefore, our results with curve-fitting to gas exchange data actually agree with anatomical differences between species.

Such differences are also shown in the fractions of refixation of (photo)respired $\mathrm{CO}_{2}$ calculated from resistance components (Fig. 5). With the distinct anatomical feature of rice leaves, (photo)respired $\mathrm{CO}_{2}$, if to exit mesophyll cells, will have to travel via the stroma, thereby maximizing the re-fixation of (photo)respired $\mathrm{CO}_{2}$ within the cell. Therefore, rice had higher values of $f_{\text {refix,cell }}$ than tomato (Fig. 5). For a given set of resistance values, the organelle arrangements as in rice leaves that make the highest $f_{\text {refix,cell }}$ can result in low $f_{\text {refix,ias }}$ (see Supplementary Text S3). Moreover, in line with the observation of Ouyang et al. (2017) on rice 'IR64', the cultivar we used, rice had high stomatal 
conductance, compared with tomato (Fig. 6). A low $g_{\text {sc }}$ would make (photo)respired $\mathrm{CO}_{2}$ more difficult to exit into the atmosphere via IAS. This also contributed to higher values of $f_{\text {refix,ias }}$ in tomato than in rice (Fig. 5). As a result, the two species had similar values (up to $60 \%$ ) of the total refixation, $f_{\text {refix }}$. The calculated $f_{\text {refix,ias }}$ and $f_{\text {refix }}$ varied with $I_{\text {inc }}$ or $C_{\mathrm{i}}$ levels (Fig. 5), because resistance components $r_{\mathrm{sc}}$ and $r_{\mathrm{cx}}$ varied with these variables. The calculated $f_{\text {refix cell }}$ was more constant (Fig. 5). Substituting Eq. (8) into Eq. (S3.5) in Supplementary Text $\mathrm{S} 3$ gives

$f_{\text {refix,cell }}=\frac{(1-\omega)(\delta+\omega \lambda k)}{(1+\delta)[\delta-\omega \lambda k(\delta+\omega-1)]}$

As all terms are constant, Eq. (9) describes why $f_{\text {refix,cell }}$ stayed invariant. Using isotope mass spectrometry and gas exchange measurements, Busch et al. (2013) determined $f_{\text {refix,cell }}, f_{\text {refix,ias }}$ and $f_{\text {refix }}$, being $0.29,0.22$, and 0.51 for rice under ambient $\mathrm{CO}_{2}$ and high light conditions. Our estimates for rice somewhat differed from their values for comparable conditions (Fig. 5d).

The difference in the value of factor $m$ between the species also has implications on values of $C_{\mathrm{i}^{*}}$ and the relationship between $C_{\mathrm{i}^{*}}$ and $\Gamma_{*} . C_{\mathrm{i} *}$ was lower in rice than in tomato at a given $\mathrm{O}_{2}$ level (Fig. 3), and $C_{\mathrm{i}^{*}}$ at the lowest $\mathrm{O}_{2}$ in rice was even negative (Fig. 3b). A negative $C_{\mathrm{i}^{*}}$ could be due to measurement noises, uncertainties in assuming constant $R_{\mathrm{d}}$, and the influence of varying amounts of $V_{\text {pepc }}$ (see earlier discussions). However, for the case where $m=0$, it can be seen from Eq. (1) that $C_{\mathrm{i}^{*}}=\Gamma_{*}-R_{\mathrm{d}} / g_{\mathrm{m}}$ (von Caemmerer et al. 1994); so, $C_{\mathrm{i}^{*}}$ is always lower than $\Gamma_{*}$. This agrees with our linear relation for rice in Fig. $3 \mathrm{~b}$ (where the term $0.16 O_{2}$ can be considered as $\Gamma_{*}$, given that $\Gamma_{*}=0.5 O_{2} / S_{\mathrm{c} / 0}$ ). Setting the intercept of this relation equal to $-R_{\mathrm{d}} / g_{\mathrm{m}}$ and knowing that $R_{\mathrm{d}}=1.064 \mu \mathrm{mol} \mathrm{m}{ }^{-2} \mathrm{~s}^{-1}$ (Fig. $2 \mathrm{~b}$ ), $g_{\mathrm{m}}$ for rice can be solved as ca $0.1 \mathrm{~mol} \mathrm{~m}^{-2} \mathrm{~s}^{-1} \mathrm{bar}^{-1}$, comparable with its value calculated in the other way for low $\mathrm{CO}_{2}$ conditions (Fig. 61). So, a negative $C_{\mathrm{i}^{*}}$ for low $\mathrm{O}_{2}$ conditions could actually represent biological realities, i.e. high intracellular refixation of both respired $\mathrm{CO}_{2}$ and photorespired $\mathrm{CO}_{2}$ sufficed to (over)compensate for photorespiratory losses. In contrast, for cases where $m \geq 0$, the relation between $C_{\mathrm{i}^{*}}$ and $\Gamma_{*}$ can be formulated from Eq. (S1.7) in Supplementary Text S1 as

$C_{\mathrm{i}^{*}}=\Gamma_{*}-\left[(1-m) R_{\mathrm{d}}-m F\right] / g_{\mathrm{m}, \mathrm{dif}}$

Equation (10) means that $C_{\mathrm{i}^{*}}$ is no longer necessarily lower than $\Gamma_{*}$ (see also Tholen et al. 2012), depending on relative values of $(1-m) R_{\mathrm{d}}$ versus $m F$. Our result in Fig. 3a suggests that $C_{\text {i* }}$ is $2.134 \mu$ bar higher than $\Gamma_{*}$ for tomato. Thus, different $m$ values estimated by curve-fitting for the two species are supported by the $C_{\mathrm{i}^{*}}$ vs $\Gamma_{*}$ relationships in Fig. 3, suggesting that our approach is internally consistent.

\section{Compliance with Ethical Standards}

Conflict of interest The authors declare that they have no conflict of interest.

Open Access This article is licensed under a Creative Commons Attribution 4.0 International License, which permits use, sharing, adaptation, distribution and reproduction in any medium or format, as long as you give appropriate credit to the original author(s) and the source, provide a link to the Creative Commons licence, and indicate if changes were made. The images or other third party material in this article are included in the article's Creative Commons licence, unless indicated otherwise in a credit line to the material. If material is not included in the article's Creative Commons licence and your intended use is not permitted by statutory regulation or exceeds the permitted use, you will need to obtain permission directly from the copyright holder. To view a copy of this licence, visit http://creativecommons.org/licenses/by/4.0/.

\section{References}

Abadie C, Tcherkez G (2019) In vivo phosphoenolpyruvate carboxylase activity is controlled by $\mathrm{CO}_{2}$ and $\mathrm{O}_{2}$ mole fractions and represents a major flux at high photorespiration rates. New Phytol 221:1843-1852

Abadie C, Bathellier C, Tcherkez G (2018) Carbon allocation to major metabolites in illuminated leaves is not just proportional to photosynthesis when gaseous conditions $\left(\mathrm{CO}_{2}\right.$ and $\left.\mathrm{O}_{2}\right)$ vary. New Phytol 218:94-106

Barbour MM (2017) Understanding regulation of leaf internal carbon and water transport using online stable isotope techniques. New Phytol 213:85-88

Barbour M, Bachmann S, Bansal U, Bariana H, Sharp P (2016a) Genetic control of mesophyll conductance in common wheat. New Phytol 209:461-465

Barbour MM, Evans JR, Simonin KA, von Caemmerer S (2016b) Online $\mathrm{CO}_{2}$ and $\mathrm{H}_{2} \mathrm{O}$ oxygen isotope fractionation allows estimation of mesophyll conductance in $\mathrm{C}_{4}$ plants, and reveals that mesophyll conductance decreases as leaves age in both $\mathrm{C}_{4}$ and $\mathrm{C}_{3}$ plants. New Phytol 210:875-889

Berghuijs HNC, Yin X, Ho QT, van der Putten PEL, Verboven P, Retta MA, Nicolaï BM, Struik PC (2015) Modelling the relationship between $\mathrm{CO}_{2}$ assimilation and leaf anatomical properties in tomato leaves. Plant Sci 238:297-311

Bernacchi CJ, Portis AR, Nakano H, von Caemmerer S, Long SP (2002) Temperature response of mesophyll conductance. Implication for the determination of Rubisco enzyme kinetics and for limitations to photosynthesis in vivo. Plant Physiol 130:1992-1998

Buckley TN, Mott KA, Farquhar GD (2003) A hydromechanical and biochemical model of stomatal conductance. Plant Cell Environ 26:1767-1785

Busch FA, Sage RF (2017) The sensitivity of photosynthesis to $\mathrm{O}_{2}$ and $\mathrm{CO}_{2}$ concentration identifies strong Rubisco control above the thermal optimum. New Phytol 213:1036-1051

Busch FA, Sage TL, Cousins AB, Sage RF (2013) $C_{3}$ plants enhance rates of photosynthesis by reassimilating photorespired and respired $\mathrm{CO}_{2}$. Plant Cell Environ 36:200-212

Busch FA, Sage RF, Farquhar GD (2018) Plants increases $\mathrm{CO}_{2}$ uptake by assimilating nitrogen via the photorespiratory pathway. Nat Plants 4:46-54

Carriquí M, Douthe C, Molins A, Flexas J (2019) Leaf anatomy does not explain apparent short-term responses of mesophyll conductance to light and $\mathrm{CO}_{2}$ in tobacco. Physiol Plant 165:604-618 
Cousins AB, Ghannoum O, von Caemmerer S, Badger MR (2010) Simultaneous determination of Rubisco carboxylase and oxygenase kinetic parameters in Triticum aestivum and Zea mays using membrane inlet mass spectrometry. Plant Cell Environ 33:444-452

Douthe C, Dreyer E, Brendel O, Warren CR (2012) Is mesophyll conductance to $\mathrm{CO}_{2}$ in leaves of three Eucalyptus species sensitive to short-term changes of irradiance under ambient as well as low $\mathrm{O}_{2}$ ? Funct Plant Biol 39:435-448

Evans JR, von Caemmerer S (2013) Temperature response of carbon isotope discrimination and mesophyll conductance in tobacco. Plant Cell Environ 36:745-756

Evans JR, von Caemmerer S, Setchell BA, Hudson GS (1994) The relationship between $\mathrm{CO}_{2}$ transfer conductance and leaf anatomy in transgenic tobacco with a reduced content of Rubisco. Aust J Plant Physiol 21:475-495

Evans JR, Kaldenhoff R, Genty B, Terashima I (2009) Resistances along the $\mathrm{CO}_{2}$ diffusion pathway inside leaves. J Exp Bot 60:2235-2248

Farquhar GD, Wong SC (1984) An empirical model of stomatal conductance. Aust J Plant Physiol 11:191-210

Farquhar GD, von Caemmerer S, Berry JA (1980) A biochemical model of photosynthetic $\mathrm{CO}_{2}$ assimilation in leaves of $\mathrm{C}_{3}$ species. Planta 149:78-90

Flexas J, Diaz-Espejo A, Galmes J, Kaldenhoff R, Medrano H, RibasCarbó M (2007a) Rapid variation of mesophyll conductance in response to changes in $\mathrm{CO}_{2}$ concentration around leaves. Plant Cell Environ 30:1284-1298

Flexas J, Diaz-Espejo A, Berry JA, Cifre J, Galmes J, Kaldenhoff R, Medrano H, Ribas-Carbó M (2007b) Analysis of leakage in IRGA's leaf chambers of open gas exchange systems: quantification and its effects in photosynthesis parameterization. J Exp Bot 58:1533-1543

Genty B, Briantais J-M, Baker N (1989) The relationship between the quantum yield of photosynthetic electron transport and quenching of chlorophyll fluorescence. Biochem Biophys Acta 990:87-92

Gu L, Sun Y (2014) Artefactual responses of mesophyll conductance to $\mathrm{CO}_{2}$ and irradiance estimated with the variable $\mathrm{J}$ and online isotope discrimination methods. Plant Cell Environ 37:1231-1249

Harley PC, Sharkey TD (1991) An improved model of C 3 photosynthesis at high $\mathrm{CO}_{2}$ : Reversed $\mathrm{O}_{2}$ sensitivity explained by lack of glycerate reentry into the chloroplast. Photosynth Res 27:169-178

Harley PC, Loreto F, Di Marco G, Sharkey TD (1992) Theoretical considerations when estimating the mesophyll conductance to $\mathrm{CO}_{2}$ flux by analysis of the response of photosynthesis to $\mathrm{CO}_{2}$. Plant Physiol 98:1429-1436

Hatakeyama Y, Ueno O (2016) Intracellular position of mitochondria and chloroplasts in bundle sheath and mesophyll cells of $\mathrm{C}_{3}$ grasses in relation to photorespiratory $\mathrm{CO}_{2}$ loss. Plant Prod Sci 19:540-551

Islam MS, Niwa Y, Takagi S (2009) Light-dependent intracellular positioning of mitochondria in Arabidopsis thaliana mesophyll cells. Plant Cell Physiol 50:1032-1040

Kebeish R, Niessen M, Thirshnaveni K, Bari R, Hirsch H-J, Rosenkranz R, Stäbler N, Schönfeld B, Kreuzaler F, Peterhänsel C (2007) Chloroplastic photorespiratory bypass increases photosynthesis and biomass production in Arabidopsis thaliana. Nat Biotechnol 25:593-599

Laisk A, Eichelmann H, Oja V, Rasulov B, Rämma H (2006) Photosystem II cycle and alternative electron flow in leaves. Plant Cell Physiol 47:972-983

Loriaux SD, Avenson TJ, Wells JM, McDermitt DK, Eckles RD, Riensche B, Genty B (2013) Closing in on maximum yield of chlorophyll fluorescence using a single multiphase flash of subsaturating intensity. Plant Cell Environ 36:1755-1770
Morison JIL, Gifford RM (1983) Stomatal sensitivity to carbon dioxide and humidity. Plant Physiol 71:789-796

Ouyang W, Struik PC, Yin X, Yang J (2017) Stomatal conductance, mesophyll conductance, and transpiration efficiency in relation to leaf anatomy in rice and wheat genotypes under drought. J Exp Bot 68:5191-5205

Peguero-Pina JJ, Flexas J, Galmes J, Niinemets Ü, Sancho-Knapik D, Barredo G, Villarroya D, Gil-Pelegrin E (2012) Leaf anatomical properties in relation to differences in mesophyll conductance to $\mathrm{CO}_{2}$ and photosynthesis in two related Mediterranean Abies species. Plant Cell Environ 35:2121-2129

Sage TL, Sage RF (2009) The functional anatomy of rice leaves: Implications for refixation of photorespiratory $\mathrm{CO}_{2}$ and effects to engineer $\mathrm{C}_{4}$ photosynthesis into rice. Plant Cell Physiol 50:756-772

Scafaro AP, von Caemmerer S, Evans JR, Atwell BJ (2011) Temperature response of mesophyll conductance in cultivated and wild Oryza species with contrasting mesophyll cell wall thickness. Plant Cell Environ 34:1999-2008

Sharkey TD (1985) $\mathrm{O}_{2}$-insensitive photosynthesis in $\mathrm{C}_{3}$ plants: Its occurrence and a possible explanation. Plant Physiol 78:71-75

Sharkey TD, Bernacchi CJ, Farquhar GD, Singsaas EL (2007) Fitting photosynthetic carbon dioxide response curves for $\mathrm{C}_{3}$ leaves. Plant Cell Environ 30:1035-1040

Sun Y, Gu L, Dickinson RE, Norby RJ, Pallardy SG, Hoffman FM (2014) Impact of mesophyll diffusion on estimated global land $\mathrm{CO}_{2}$ fertilization. Proc Natl Acad Sci USA 111:15774-15779

Tazoe Y, von Caemmerer S, Badger MR, Evans JR (2009) Light and $\mathrm{CO}_{2}$ do not affect the mesophyll conductance to $\mathrm{CO}_{2}$ diffusion in wheat leaves. J Exp Bot 60:2291-2301

Tazoe Y, von Caemmerer S, Estavillo GM, Evans JR (2011) Using tunable diode laser spectroscopy to measure carbon isotope discrimination and mesophyll conductance to $\mathrm{CO}_{2}$ diffusion dynamically at different $\mathrm{CO}_{2}$ concentrations. Plant Cell Environ 34:580-591

Tcherkez G, Limami AN (2019) Net photosynthetic $\mathrm{CO}_{2}$ assimilation: more than just $\mathrm{CO}_{2}$ and $\mathrm{O}_{2}$ reduction cycles. New Phytol 223:520-529

Tcherkez G, Gauthier P, Buckley TN et al (2017) Leaf day respiration: low $\mathrm{CO}_{2}$ flux but high significance for metabolism and carbon balance. New Phytol 216:986-1001

Terashima I, Hanba YT, Tholen D, Niinemets Ü (2011) Leaf functional anatomy in relation to photosynthesis. Plant Physiol 155:108-116

Théroux-Rancourt G, Gilbert ME (2017) The light response of mesophyll conductance is controlled by structure across leaf profiles. Plant Cell Environ 40:726-740

Tholen D, Ethier G, Genty B, Pepin S, Zhu X-G (2012) Variable mesophyll conductance revisited: theoretical background and experimental implications. Plant Cell Environ 35:2087-2103

Tomas M, Flexas J, Copolovici L, Galmes J, Hallik L, Medrano H, Ribas-Carbo M, Tosens T, Vislap V, Niinemets Ü (2013) Importance of leaf anatomy in determining mesophyll diffusion conductance to $\mathrm{CO}_{2}$ across species: quantitative limitations and scaling up by models. J Exp Bot 64:2269-2281

Tosens T, Niinemets Ü, Vislap V, Eichelmann H, Castro Diez P (2012a) Developmental changes in mesophyll diffusion conductance and photosynthetic capacity under different light and water availabilities in Populus tremula: how structure constrains function. Plant Cell Environ 35:839-856

Tosens T, Niinemets Ü, Westoby M, Wright IJ (2012b) Anatomical basis of variation in mesophyll resistance in eastern Australian sclerophylls: news of a long and winding path. J Exp Bot 63:5105-5119

Ubierna N, Cernusak LA, Holloway-Phillips M, Busch FA, Cousins AB, Farquhar GD (2019) Critical review: incorporating the arrangement of mitochondria and chloroplasts into models of 
photosynthesis and carbon isotope discrimination. Photosynth Res 141:5-31

van der Putten PEL, Yin X, Struik PC (2018) Calibration matters: on the procedure of using the chlorophyll fluorescence method to estimate mesophyll conductance. J Plant Physiol 220:167-172

von Caemmerer S (2000) Biochemical models of leaf photosynthesis, vol 2. CSIRO Publishing, Collingwood

von Caemmerer S (2013) Steady-state models of photosynthesis. Plant Cell Environ 36:1617-1630

von Caemmerer S, Evans JR (1991) Determination of the average partial pressure of $\mathrm{CO}_{2}$ in chloroplasts from leaves of several $\mathrm{C}_{3}$ plants. Aust J Plant Physiol 18:287-305

von Caemmerer S, Evans JR, Hudson GS, Andrews TJ (1994) The kinetics of ribulose-1,5-bisphosphate carboxylase/oxygenase in vivo inferred from measurements of photosynthesis in leaves of transgenic tobacco. Planta 195:88-97

Vrábl D, Vašková M, Hronková M, Flexas J, Šantrůček J (2009) Mesophyll conductance to $\mathrm{CO}_{2}$ transport estimated by two independent methods: effect of variable $\mathrm{CO}_{2}$ concentration and abscisic acid. J Exp Bot 60:2315-2323

Warren CR, Dreyer E (2006) Temperature response of photosynthesis and internal conductance to $\mathrm{CO}_{2}$ : results from two independent approaches. J Exp Bot 57:3057-3067

Yamori W, Noguchi K, Hanba YT, Terashima I (2006) Effects of internal conductance on the temperature dependence of the photosynthetic rate in spinach leaves from contrasting growth temperatures. Plant Cell Physiol 47:1069-1080

Yin X, Struik PC (2009) Theoretical reconsiderations when estimating the mesophyll conductance to $\mathrm{CO}_{2}$ diffusion in leaves of $\mathrm{C}_{3}$ plants by analysis of combined gas exchange and chlorophyll fluorescence measurements. Plant Cell Environ 32:1513-1524 (corrigendum in 33:1595)

Yin X, Struik PC (2017) Simple generalisation of a mesophyll resistance model for various intracellular arrangements of chloroplasts and mitochondria in $\mathrm{C}_{3}$ leaves. Photosynth Res 132:211-220

Yin X, Struik PC, Romero P, Harbinson J, Evers JB, van der Putten PEL, Vos J (2009) Using combined measurements of gas exchange and chlorophyll fluorescence to estimate parameters of a biochemical $\mathrm{C}_{3}$ photosynthesis model: a critical appraisal and a new integrated approach applied to leaves in a wheat (Triticum aestivum) canopy. Plant Cell Environ 32:448-464

Yin X, Sun Z, Struik PC, Gu J (2011) Evaluating a new method to estimate the rate of leaf respiration in the light by analysis of combined gas exchange and chlorophyll fluorescence measurements. J Exp Bot 62:3489-3499

Publisher's Note Springer Nature remains neutral with regard to jurisdictional claims in published maps and institutional affiliations. 